\title{
Fuel Filtration Properties and Mechanism of a Novel Fibrous Filter Produced by a Melt-Process
}

\author{
Jia Wang ${ }^{1, *}$, Michael Ponting ${ }^{2}$, Cong Zhang ${ }^{1}$, Andrew Olah ${ }^{1}$, and Eric Baer ${ }^{1}$ \\ ${ }^{1}$ Center for Layered Polymeric Systems \\ Department of Macromolecular Science and Engineering \\ Case Western Reserve University \\ 2100 Adelbert Rd. \\ Cleveland, $\mathrm{OH}$ \\ ${ }^{2}$ PolymerPlus, LLC \\ 7700 Hub Pkwy, Valley View, OH 44125
}

*Telephone: 1-513-378-0836; Email: jxw474@ case.edu

Emails of co-authors: mponting@polymerplus.net;

cxz177@ case.edu;

amo5@case.edu;

exb6@case.edu

Key Words: Fibrous filter, Fuel filtration, Droplet capture, Droplet run-off, Mechanism 


\begin{abstract}
A porous filter comprised of polypropylene (PP) / polyamide 6 (PA6) micro-/nano-fibers has been produced from a novel melt-based plastics co-extrusion and exfoliation process technology for the separation of microscale water droplets from diesel fuel. The filter media have a mean pore size of $11 \mu \mathrm{m}$, a porosity greater than $85 \%$, a surface area of more than $12 x$ the value for an electrospun medium, tough mechanical properties, and a contact angle of $124^{\circ}$, all of which make the co-extruded filter a superior fuel filter. An improvement in water-separation from diesel fuel feed stream from $62 \%$ to $85 \%$ water-removal was achieved by the co-extruded and exfoliated PP/PA6 fibrous media in comparison to a commercial fuel filter under identical test conditions and pressure drop. The fuel/water separation mechanism was identified as a capture-coalescencerelease process. It has been found that the highest performance fuel filter required small pore sizes and large surface area for droplet capture, due to the hydrophobic nature of materials required for successful droplet release, and a high porosity for minimizing flow resistance. In addition to the proof of concept water separation demonstration, studies into (a) the effect of increasing the barrier substrates thickness and (b) surface corona treatment to alter the hydrophilicity of media surfaces on the filtration efficiency co-extruded, exfoliated filters are reported.
\end{abstract}




\section{Introduction}

Water in diesel fuel is problematic as it can impact the lubricative properties of fuel, and can freeze in sub-zero conditions restricting fuel flow and/or damaging the engine system. [1] Major filtration challenges lie in the removal of emulsified water with droplet size of less than 100 $\mu \mathrm{m}$. [2] In terms of the water-removal capability, including emulsified water droplets, fuel filters can be classified into three types as they are invented sequentially; conventional cellulosic, coatedcellulosic, and advanced layered composites. The conventional and probably the lowest-cost commercial fuel filters are produced from the hydrophilic cellulosic fibers, which are ribbon-like fibers with widths around 10-20 $\mu \mathrm{m}$. [3] Because of the large fiber lateral size, large pores exist throughout the filter media. Therefore, these filters exhibit limited capability to remove water droplets smaller than the pore dimensions, which are the most problematic. Their excessive hydrophilicity can in addition result in clogging by accumulated water that requires greater energy input to overcome the larger pressure drop as a result. Silicone treatments have been employed to reduce the filter hydrophilicity/water-wettability. Despite the mitigation of clogging, siliconetreated cellulose fuel filters reject water by a stripping process [1], and therefore inherit the low filtration efficiency issue due to large pore sizes. More advanced fuel filters employ an additional microfiber layer with small pore sizes to remove the emulsified water droplets. This functional layer is generally produced using a melt-blowing [4] or an electrospinning technique [2], which requires complicated set-up or use of organic solvents. In addition, the cellulose fiber layer remains necessary as a substrate, for the micro-/nano-fiber layers have poor mechanical strength that they cannot hold themselves.

Due to the limited filtration efficiency and durability of the current truck fuel filter, there have been great needs for fuel filtration media: 1. having superior performance in water rejection/removal, particularly those emulsified micron-sized droplets; 2. showing strong and tough mechanical properties to withstand the pressure drop necessary in filtration systems; and 3. produced from an environmental-friendly solvent-free technique. Novel filters have been developed using a novel melt-based co-extrusion technology for fuel filtration application. [5-7] One of the advantages of this process is that no organic solvent is involved as it is purely meltbased. Also, because the microfibers that eventually form the filter material are aligned as they are embedded in the extruded tapes, these microfibers are capable of being structurally oriented and strengthened to produce filters with superior mechanical properties than those made from blow- 
molding or electrospinning techniques. [5-7] The enhanced filter surface area as a result of rectangular fibers in the co-extruded filters further facilitates catching and exclusion of water droplets. Furthermore, these water separators are comprised of mixed fibers of both hydrophilic and hydrophobic polymers, and therefore show an intermediate hydrophilicity for optimum filtration performances.

In order to evaluate the filtration performance of these co-extruded fibrous filters, the filtration mechanism is studied in detail. A fuel filtration procedure is comprised of three stages: first, the filter catches the water droplets on its fibers; second, the droplets migrate through the filter thickness direction and coalesce into bigger drops; and third, the large droplets move to the bottom of the filter due to its higher density compared to fuel. [2] Filter characteristics that could influence the filtration properties in these three stages include the structural features, such as the filter pore size, porosity, surface area, and filter thickness; and the chemical variables, including material hydrophilicity and filter surface modifications. In the past, extensive research has been performed to study the water separation performance as a function of the filter media hydrophilicity. [2, 8-19] Researchers hold different opinions toward the most desirable wettability: Voyutskii et al. claimed that an intermediate wettability was optimal to facilitate water droplets coalescence, yet not to generate clogging. [8] Fuel fibrous media comprised of mixed or coupled hydrophilic and hydrophobic materials were reported to have intermediate hydrophilicity and the optimum separation properties. [2, 9-12] Another study favored a hydrophilic material by explaining the water-capturing mechanism with the replacement of oil by water droplets on the fibers. $[13,14]$ Some other research work claimed that super-hydrophobic eletrospun nanofiber media showed superior water separation performances. [15-18] Opinions also exist that filtration was not dependent on the hydrophilicity of the filter material. [19]

Despite the extensive focus on the water coalescence behavior dependent on the filter hydrophilicity, the actual microfiltration mechanism has not been well studied. Particularly, the water-releasing procedure has not been well studied. Hazlett claimed a 3-step capture-attachmentrelease procedure as the fuel/water separation mechanism. However, the theory was based on the interaction of water droplets and a single fiber or a completely ordered fiber bed system, which are far less complicated than a real fibrous media. Besides, the estimated detaching droplet size was referred to the diameter of the coalesced droplets that were yet to be removed. [13,14,20] Similarly, Krasinski calculated the detaching water droplet size, yet it was for a mesh filter with 
certain square void sizes and fiber diameters. [21] Taking into account that the water droplet size in focus is similar or larger than the filter fiber size and pore size, it is the interaction between a water droplet and a small area of the filter media that needs to be studied rather than that between a water droplet and a single fiber. The alignment of this small piece of filter media needs to be taken into account when analyzing the interaction, for it is crucial for water droplet holding and run-off behavior. Besides the investigation of the influences of filter hydrophilicity on the water removal properties, this paper studies the interaction between water and this small area of filter media from a new perspective: by mimicking the droplet exclusion procedure using a tilting filter, and establishes a relationship between the tilting angle and the droplet run-off ability. In addition, the effects of filter pore size and filter thickness on the filtration performance have also been investigated.

\section{Materials and Methods}

\section{Materials}

Polypropylene (PP Exxon Mobil 2252 E4) and polyamide 6 (PA6 BASF Ultramid B 36 01) were used as received to produce fibers in fuel filters. The supplier-provided polymer densities are $0.9 \mathrm{~g} / \mathrm{cm}^{3}$ and $1.13 \mathrm{~g} / \mathrm{cm}^{3}$ for PP and PA6, respectively. Polystyrene (PS Dow 685D) was used as the separating material in the extrusion procedure. A pure hydrocarbon liquid, Viscor 1487, was employed as the replacement for diesel fuel in the filtration efficiency tests for it contains no additives to suppress water droplet coalescence.

\section{The production of the PP/PA6 composite fibrous filters}

As described in our earlier work for producing polymeric micro-/nano-fibers and fibrous mats [5-7], tapes containing 8192 by 32 alternating PP and PA6 continuous fiber domains and 33 PS separating domains were produced through a continuous co-extrusion and two-dimensional multiplication process. The extrusion was performed at a total throughput of $1.6 \mathrm{~kg} / \mathrm{hr}$. at $255^{\circ} \mathrm{C}$, where the viscosities of PP, PA6, and PS match with each other. As shown in Figure 1, PP and PA6 resins were melted and layered into a flow containing two rectangular flow fields, which was vertically multiplied 18 times to form $2^{18}$ (262144) vertical PP/PA6 layers, followed by the addition of PS separating material from the top and bottom. This flow of three horizontal sections was horizontally multiplied 5 times to generate a matrix-like structure. The continuous melt flow of PP/PA6/PS with a volume composition of 45.5/45.5/9 (PP/PA6/PS) was extruded through a 
spreading die with a width of $75 \mathrm{~mm}$, and formed a continuous composite tape having a cross section of $130 \mu \mathrm{m}$ by $52 \mathrm{~mm}$ on chill roll at $80^{\circ} \mathrm{C}$. A mechanical orientation procedure was performed on the PA6/PP tapes for improving the crystal orientation and mechanical properties of the PP and PA6 fibers using an Instron 5965 unit. The fibrous tapes were oriented at $130^{\circ} \mathrm{C}, 1000$ $\% / \mathrm{min}$ to $4.0 \mathrm{x}$, followed by a second orientation step to $4.5 \mathrm{x}$ at $155^{\circ} \mathrm{C}, 100 \% / \mathrm{min}$.

The PA6/PP fibrous filters were fabricated from stacked oriented tapes in cross-ply manner via a water jetting technique [5-7]. High pressure water jets were generated from a 254 micron nozzle with a nozzle pressure of 6.89 MPa. PA6/PP tape cross-ply was placed on a steel plate with their ends fixed. The overlapping area was $50 \mathrm{~mm}$ by $50 \mathrm{~mm}$ in size, and was covered by an aluminum grid of mesh size \#60 (30\% open area). The water nozzle was placed $50 \mathrm{~mm}$ above the set-up, and moved at a linear speed of $25.4 \mathrm{~mm} / \mathrm{s}$ in a scanning fashion to delaminate and entangle the PP and PA6 fibers, and to break down and remove PS [5-7]. The cross-ply was jetted for 5 minutes, and was flipped to expose the opposite side to jetting for another minute. Three- and fourplied filters were fabricated by water jetting three and four tapes with a $90^{\circ}$ between each adjacent two tapes. The wet filters post water jetting were dried in a vacuum oven at $60{ }^{\circ} \mathrm{C}$ for $12 \mathrm{~h}$.

\section{Treatment of the PP/PA6 filters}

The PP/PA6 fibrous filters were subjected to corona treatment for improved hydrophilicity using a BD-20 corona treater from Electro-technic Products, Inc. The filters were cut into a round sample with diameter of $25.4 \mathrm{~mm}$, and was placed $5 \mathrm{~mm}$ below the applicator with a voltage of $10,000 \mathrm{~V}$. The applicator moved at $50 \mathrm{~mm} / \mathrm{s}$ in a scanning fashion to cover the area of the filter for 10, 30, and 60 seconds. The surface functional groups were characterized using a continuum FTIR/ATR by Spectra-tech at 32 scans.

The surface hydrophilicity of the filters was characterized by water contact angle measurement using the CAM 200 Optical Contact Angle Meter from KSV Instrument. Due to the fact that the water droplets spread on and penetrated in the filter samples, optical images of the water droplets were captured instantly and 10, 15, 30, 60, 120, and 300 seconds after dropping the water on the filter surfaces. The water contact angles of the initial polymer materials were also tested. The filter tilting angle at water droplet instability was characterized to quantify the filter's capability to release the coalesced water drops. Water droplets with a volume ranging from 45 to $80 \mu \mathrm{L}$, controlled by a WPI 220I syringe pump, were dropped on a PP/PA6 filter plane with a 
tilting angle continuously increased from $0^{\circ}$ until the droplet started to roll on the filter surface. This critical tilting angle and droplet size were recorded as the tilting angle at instability for this specific droplet size, and was correlated to the tilting angle at droplet instability.

\section{Structural characterization of PA6/PP tape, PP/PA6 fibrous filter, and a commercial fuel filter}

The thermograph of the as-extruded tape was generated using a TA Instruments Q2000 Differential Scanning Calorimetry (DSC) by heating from 0 to $300{ }^{\circ} \mathrm{C}$ at $10{ }^{\circ} \mathrm{C} / \mathrm{min}$ (Figure 2, a). The crystal orientations of PP and PA6 were characterized using a Rigaku 2D Wide Angle X-ray Diffraction (WAXD) unit using the $\mathrm{Cu} \mathrm{K} \alpha$ radiation source $(\lambda=1.5405 \AA)$ at room temperature. The beam time was 3 hours/sample (Figure 2, b and c).

The cross section and surface of the 2-plied PA6/PP filter and the commercial filter were observed using a JEOL SEM. The widths and thicknesses of 50 individual PP/PA6 fibers were measured for determining the average fiber dimensions. The stress-strain behaviors of the PP/PA6 fibrous filter and the commercial filter were tested using an Instron 5965 unit at room temperature following ASTM D828 standard. A specimen width of $25.4 \mathrm{~mm}$ and a gauge length of $50.8 \mathrm{~mm}$ were used. The tests were done at a $25.4 \mathrm{~mm} / \mathrm{min}$ strain rate.

The BET surface area of the filters was measured using krypton gas by a Micromeritics Tristar II unit (Norcross, GA). Filter thicknesses were measured according to the ASTM D5729 standard using an MTS 5565 (compression) unit on round filter samples having diameter of 25.4 $\mathrm{mm}$. The mean pore size and pore size distribution of the PP/PA6 fibrous filters and a commercial grade polyester/cellulosic paper-based composite filter [3] were characterized using a Quantachrome 3G Macro Porometer. The tests were based on the ASTM F316 standard for the through-pore characteristics of membrane filters. A proprietary fluoro-based liquid "Porofil" provided by Quantachrome was used as the wetting liquid. The tests were performed in the pore size range of 300 to $2 \mu \mathrm{m}$, and 256 points were taken in each measurement. The filter porosity was determined using a density method as defined in Equation 1:

$$
\text { Porosity }=\left(1-\frac{\rho_{\text {bulk }}}{\rho_{\text {polymer }}}\right) \times 100 \%
$$

The filters' bulk density $\rho_{\text {bulk }}$ was calculated from the weight and volume of the filters, whereas the volume was calculated from the filter's diameter and thickness. The polymer density of a mixed fibrous system (PP and PA6) $\rho_{\text {polymer }}$ was obtained by averaging the original polymer 
densities (provided by the suppliers and listed in Table 1) based on the volume fractions of each component, assuming that all the small amount PS domains were completely removed.

\section{Filtration property test}

The filtration properties were tested using a filtration set-up (Figure 3) following the guideline of SAE1488 standard, except that no recycle flow line was built and only one-pass tests were performed. The system is comprised of a 10L tank containing the fuel/water mixture, a Fesco Industries centrifugal pump to emulsify the fuel/water mixture, a Cole-Parmer fuel peristaltic pump to transfer the liquid, a flowmeter with max capacity of $10 \mathrm{gph}$, a customized filter holder with drainage, a pressure gauge, and upstream and downstream sample ports.

The fuel/water mixture containing $2500 \mathrm{ppm}$ water was prepared by mixing the two components in a $1000 \mathrm{~mL}$ beaker using a magnetic stirrer bar stirring at $1000 \mathrm{rpm}$ for 1 hour, followed by emulsification using the centrifugal pump for $10 \mathrm{~min}$. The filter sample with diameter of 1" was placed vertically in the filter holder, the way it is used in vehicles, and was sealed by an O-ring with the same size. The fuel/water mixture liquid was pumped to the filter at a rate of 4 gph. Both the influent and the effluent liquids were collected with a sample size of $10 \mathrm{~mL}$ at 30 , $60,90,120$, and 300 seconds after the initiation of flow, respectively. The differential pressure (pressure drop) across the filter was simultaneously recorded.

The water droplet diameter was observed using a BHM optical microscope. 3 images of the same sample were taken, and the size of each droplet was measured. The water concentration was detected using a Mettler Toledo DL38 Karl Fischer Titrator. Hydranol-Composite 5 titrant was used to supply iodine, which reacts with water in an equimolar reaction. Methanol was used as the solvent. The fuel/water liquid sample was transferred using a syringe, and was sonicated for $10 \mathrm{~min}$ before measurement. The water concentration was determined using Equation 2:

$$
C_{\text {water }}=\frac{M_{\text {water }} \cdot n_{I_{2}}}{m_{\text {fuel } / \text { water }}}
$$

Whereas $M_{\text {water }}$ is the molar mass of water, $n_{I_{2}}$ is the molar number of iodine monitored by the titrator, and $m_{f u e l} /$ water is the mass of the fuel/water mixture liquid measured as the difference of the syringe mass before and after the addition of the liquid sample into the titrator. 
The filtration efficiency $\varepsilon$ of a filter is defined as Equation 3, whereas $C_{\text {water,inf fluent }}$ and $C_{\text {water,effluent }}$ are the water concentration in the influent and effluent fluids, respectively.

$$
\varepsilon=\left(1-\frac{C_{\text {water, }, \text { ffluent }}}{C_{\text {water, inf fluent }}}\right) \times 100 \%
$$

\section{Results and Discussion}

\section{PP/PA6 fibrous filters from oriented tapes}

The effects of the post extrusion mechanical orientation of tapes were evaluated by comparing the WAXD patterns of the PA6/PP tape stretched to 4.5x ratio. For the as-extruded (unoriented) sample, Figure 2b, full circle x-ray diffraction patterns were observed for the PP (110), (040), (130), and (111/041) reflection planes along with the PS amorphous halo [23, 24]. Clear PA6 crystal reflections were not observed in the extruded, un-oriented tape sample. These patterns indicated random crystal orientation of PP and PA6 in the fiber domains of the as-extruded tape. The PA6/PP tape was drawn to 4.0x in first step, followed by orientation to a maximum draw ratio of 4.5x, in an effort to achieve highest possible stretching and crystal orientations of the PA6 and PP domain in the fibers. The WAXD pattern in Figure 2c, displayed sharp reflections on the equator at $2 \theta=14.2^{\circ}, 17.0^{\circ}, 18.6^{\circ}, 20.6^{\circ}$ and $23.1^{\circ}$, referring to the PP (110), PP (040), PP (130), PA6 ( $\alpha 200)$, and PA6 ( $\alpha 002 / 202)$ planes, respectively. [25] These prominent peaks for PP and PA6 crystals indicate that the PP and PA6 crystals were highly oriented along the tape axis as the draw ratio of the composite tape increased.

These oriented and strong fibrous tapes were water-jetted to form the fibrous filters. The PP and PA6 fibers were delaminated at their interface under the water jet impact pressure. Delamination rather than fiber breakage was achieved due to the strong mechanical properties of oriented PP and PA6, and the weak interface between the two. The adhesion between polymer domains can be characterized by the interphase thickness defined by Equation 4:

$$
\mathrm{d}_{\mathrm{I}}=\frac{2 \mathrm{~b}}{(6 \chi)^{0.5}}
$$

Whereas $\mathrm{b}=5.5 \dot{\mathrm{A}}$, and $\chi_{\mathrm{AB}}=\frac{\mathrm{V}}{\mathrm{RT}}\left(\delta_{\mathrm{A}}-\delta_{\mathrm{B}}\right)^{2} . \delta_{\mathrm{A}}$ and $\delta_{\mathrm{B}}$ are the solubility parameters for PP and PA6, respectively. The larger the interphase thickness, the stronger the adhesion. In 
case of PP/PA6 interphase, the thickness is as small as $0.29 \mathrm{~nm}$, therefore the PP and PA6 micro/nano-fibers can be relatively easily delaminated.

The separate fibers vibrated and entangled with each other to form an integrated filter structure. As shown in Figure 4 (a), the cross-plied PP/PA6 fibrous filter has apparent two-layered structure with delaminated PP and PA6 fibers. These micro-/nano-fibers have ribbon-like shapes (Figure $4, \mathrm{~b}$ ), and the average fiber lateral dimensions are $3.7 \pm 3.3 \mu \mathrm{m}$ by $0.85 \pm 0.51 \mu \mathrm{m}$ summarized from 50 fibers. The filter surface area is $2.9 \mathrm{~m}^{2} / \mathrm{g}$, which is around 10 -fold larger surface area [7] in comparison with the electrospun fiber mat having similar fiber sizes. This is attributed to the rectangular, ribbon-like micro/nano-fibers produced from the 2D multiplication and orientation, and the successful fiber delamination.

\section{Comparison of the structure and filtration properties of the PP/PA6 fibrous filter and a commercial fuel filter}

The structure, morphology and properties of the PP/PA6 cross-plied filter were compared with a commercial fuel filter. As shown in Figure 4 (c)-(e), the commercial filter is comprised of two layers, with the top layer made from meltblown polyester microfibers, and the bottom layer being a cellulosic fibrous substrate. [3] The active filtration layer is the top microfiber layer containing cylindrical microfibers of $0.2 \sim 7 \mu \mathrm{m}$ in diameter. The bottom cellulose-fiber-layer has flat fibers with fiber widths ranging from 5 to $20 \mu \mathrm{m}$. This layer provides mechanical support for the top layer, due to the fact that meltblown microfiber materials have inferior mechanical properties and could not withstand the pressure difference during filtration. In contrast, both plies in the PP/PA6 fibrous filter act as a functional filtration layer, for they both are comprised of strengthened PP and PA6 microfibers with aligned crystal orientations to provide superior mechanical performance.

As shown in Figure 5, the commercial filter shows a very rigid and brittle mechanical behavior, while the PP/PA6 fibrous filter has higher tensile strength and significantly larger

toughness, which is around $6 \mathrm{x}$ the value for the commercial filter as listed in Table 2. As both tensile strength and toughness are critical for the fabrication of an endurable filter in the fuel filtration industry, the PP/PA6 fibrous filter shows more promising durability than the current commercial filter under consideration. 
The cross-plied PP/PA6 filter was fabricated to have a similar thickness, $0.74 \mathrm{~mm}$, to that of the double-layered commercial filter (Table 3) for comparison purpose. For successful water droplet filtration, a desirable filter should have: 1. high surface area, which can facilitate water droplet catching; 2. small pore size for blocking the water droplets from penetrating the media; and 3. high porosity to reduce the pressure drop and to save the energy needed to drive the flow through the filter. Surface area of a fibrous media is dependent on the fiber size, and both filters are composed of micro-/nano-fibers with comparable lateral dimensions: $3.7 \pm 3.3 \mu \mathrm{m}$ by $0.85 \pm$ $0.51 \mu \mathrm{m}$ for the PP/PA6 filter, and 0.2-7 $\mu \mathrm{m} / 5-20 \mu \mathrm{m}$ in diameter for the commercial filter. However, due to the rectangular shape of the PP and PA6 microfibers, the PP/PA6 filter has a much higher surface area (more than $12 x$ ) to the commercial filter as listed in Table 3. The PP/PA6 filter also has a $1 / 3$ smaller mean pore size, which is $11 \mu \mathrm{m}$ compared to $17 \mu \mathrm{m}$ as shown in Figure 6. A higher porosity was achieved form the PP/PA6 filter than the commercial filter (Table 3). These critical superior properties of the PP/PA6 fibrous filter favor the filtration of water droplets from diesel fuel, and make the filter a more desirable fuel filtration media.

The fuel filtration performance results confirm the advantages of the PP/PA6 porous fiber separator. As shown in Figure 7 (a), the influent fuel/water mixture contains a large quantity of well dispersed water droplets with a wide size distribution (Figure 7, b). The corresponding water concentration is $(2.49 \pm 0.04) \times 10^{3} \mathrm{ppm}$. After the filtration using the commercial filter at a pressure drop of $0.8 \mathrm{psi}$ (Table 3$)$, the water concentration decreased to $(9.5 \pm 0.9) \times 10^{2} \mathrm{ppm}$, which is a $62 \%$ reduction. In comparison, filtration with the PP/PA6 fibrous filter performed at the same flow rate showed a lower pressure drop of $0.7 \mathrm{psi}$. The water concentration was reduced to $(3.7 \pm 0.3) \times 10^{2} \mathrm{ppm}$, standing for an enhanced filtration efficiency of $85 \%$ as listed in Table 3 .

Larger drops than the filter pores can be directly blocked, held, coalesced, and removed from the main flow, while the smaller ones have a tendency to penetrate the filters. As shown in Figure 7 (b), the majority ( $60 \%)$ of the droplets in the influent have a diameter greater than 11 $\mu \mathrm{m}$, which is the mean pore size of the PP/PA6 filter; while only $30 \%$ water droplets are larger than the mean pore size of the commercial filter, $17 \mu \mathrm{m}$. This difference leads to better filtration performance for the PP/PA6 filter. As shown in Figure 7 (c-f), for both filters, the numbers for water droplets were largely decreased confirming successful filtration. The effluent liquid from the PP/PA6 filter showed smaller amount of droplets than that from the commercial filter in accordance with the water concentration data. Migration of the droplet size distribution toward 
larger sizes is indicative of the coalescence effect of water droplets by the filter media. Both filters showed droplet coalescence effect probably due to their hydrophilic filter components, which are cellulose and PA6, respectively.

From the filtration point of view, the superior filtration efficiency of the PP/PA6 filter over the commercial sample can be attributed to its smaller pore size that blocks more water droplets from penetration. The water contact angles of the PP/PA6 filter and the commercial filter are $124^{\circ}$ and $130^{\circ}$, respectively, as a result of the wettability of their component materials and their surface roughness. Although the two filters have similar intermediate hydrophilicities, the much greater surface area of the PP/PA6 filter (12x) significantly contribute to the more effective acquisition of small water droplets, and further improves the filtration efficiency. The pressure drops across the filters are more closely related to the filter porosity than the filter pore size: there seems to be an inverse relationship between the pressure drop and the filter porosity.

\section{Effect of filter thickness on Filtration properties}

Adjusting the filter thickness is probably the most straightforward route to improve the filtration efficiency. To probe these effects and to potentially achieve improvements in filtration performance, the PP/PA6 filters were fabricated from different number of plies, and were characterized for filter thickness, fiber lateral dimensions, filter surface area, pore size, and porosity as listed in Table 4. As the ply number increased from 2 to 4 , the filter thickness increased from $0.74 \mathrm{~mm}$ to $1.38 \mathrm{~mm}$, which is almost proportional to the change in the ply number. The slight discrepancy from direct proportionality is due to the interaction of fibers amongst adjacent plies in the filter thickness direction during water jetting process. It can be reasonably assumed that the fiber lateral dimensions and surface area were unaffected for this series of filters, and the porosity remained at $87 \sim 88 \%$ as the ply number changes because of the consistency of the coextrusion and water jetting procedure. The effective filter pore size is reduced from $11 \mu \mathrm{m}$ to 5.4 $\mu \mathrm{m}$ with a suppressed pore size distribution width as the ply number increases from 2 to 4 (Figure 8 and Table 4). This is due to longer and more tortuous paths of liquid in the through-pore direction for the thicker filter.

In comparison with the water droplet sizes, $90 \%$ of the pore sizes of the 4-plied filter are smaller, and therefore can effectively block these water droplets. As listed in Table 4, the effluent water concentration drastically decreased from $(2.49 \pm 0.04) \times 10^{3} \mathrm{ppm}$ to less than $400 \mathrm{ppm}$ after 
filtration using the 2-plied filter, representing the removal of $85 \%$ water content from the mixture. When increasing the number of plies to 4 , the effluent water concentration was further reduced to $(2.0 \pm 0.4) \times 10^{2} \mathrm{ppm}$, equal to a filtration efficiency of $92 \%$, which is $7 \%$ higher than the value for the 2-plied filter. As a trade-off, the pressure drop increased from 0.7 to 3.3 psi with increasing filter thickness, due to increasing tortuosity and length of the path through the filters.

Overall, increasing the ply number generates thicker filters with largely increased filtration path length and tortuosity through the filter media, and therefore results in much smaller effective filter pores that can stop and remove a greater number of water droplets. However, the improvement of the filtration efficiency was achieved at the cost of a drastically increased crossmembrane pressure.

\section{Effect of filter surface hydrophilicity on filtration properties}

Due to the fact that the majority of the water droplets are larger than both the filter mean pore size and the fiber size, it is the interaction between water droplets and a small area of filter media that takes place rather than the interaction between droplet and a single fiber. As claimed in prior art, the filter hydrophilicity influences the catching and coalescence of the water droplets. The surface hydrophilicity of the filter was therefore altered to investigate its effect on the fuel filtration properties, and the filter thickness was kept constant.

Polypropylene is a hydrophobic, chemically inert material with a water contact angle of $103^{\circ}$ (Figure 9, a) and low surface energy, and therefore is not easily wetted with water droplets. Oxidation with the corona treatment occurs at the tertiary carbons on PP molecules, and generates functional groups, such as $-\mathrm{OH}$ and $\mathrm{C}=\mathrm{O}$, on the filter surfaces leading to improved water adhesion properties. PA6 has an intermediate hydrophilicity with a water contact angle of $67^{\circ}$ (Figure 9, b). The extent of oxidation was varied by increasing the corona treatment time from 10 to 60 seconds.

As shown in Figure 9 (c)-(h) and list in Table 5, the water contact angle of the PP/PA6 fibrous filter decreased as they are exposed to longer corona treatment. The un-treated filter surface exhibited high hydrophobicity with a water contact angle of $124^{\circ}$, higher than the values for its components PP and PA6, due to the surface roughness in microscale of the fibrous media. The surface of the filter subjected to corona treatment for 10 seconds (10s-treated filter) showed almost the same water contact angle, $125^{\circ}$, as the un-treated filter when tested immediately after water contact. However, this value gradually decreased to $78^{\circ}$ after 300 seconds, as the water droplet 
spread and permeated into the filter media. Due to the filter's porous structure, not only the filter surface was corona-modified, chemical oxidation also occurred on the fibers that resided inside the filter but close to the filter surface as long as they are partially exposed to the corona plasma. Therefore, a gradient in the hydrophilicity was generated in the filter thickness direction, whereas the filter surface was the most hydrophilic, and the fibers deeper inside the filter surface gradually are more hydrophobic. During the water contact angle test, the water droplet started to migrate into the filter media due to increased hydrophilicity of the subsurface fibers, and filled up the porous structure until it reached the hydrophobic fibers far from the surface that were not exposed to sufficient corona treatment. As the treatment time increased, it seems that the surface fibers are more intensely oxidized, and the effect of corona treatment seems to reach the fibers deeper in the filter. Treating the filter surface with corona for 30 and 60 seconds further increased the filter hydrophilicity characterized by the lower contact angle tested after the same elapsed time and much quicker water absorption (Figure 9, f-I and Table 5).

The extent of filter surface oxidation was confirmed by the FTIR/ATR test results. As shown in Figure 10 (a) for the PP film material, the corona-treated filter showed apparent peaks at $3300 \sim 3400 \mathrm{~cm}^{-1}, 1700 \sim 1750 \mathrm{~cm}^{-1}$, and 1000 1100 $\mathrm{cm}^{-1}$, which referred to the $-\mathrm{OH}, \mathrm{C}=\mathrm{O}$, and CO groups, respectively. In comparison, no peak was observed in these regions for the untreated filter. This result confirms that the PP material can be oxidized owning to its unstable tertiary carbons, and became more water-wetting. In addition, the peak intensities were enhanced as the treatment time increased, indicating a greater extent of chemical modification of PP. The same oxidation results were observed for the PP component in the PP/PA6 filter (Figure 10, b). As both the $-\mathrm{OH}$ and $\mathrm{C}=\mathrm{O}$ groups are abundant in PA6 even for the untreated sample, the peak standing for the C-O group was used at an indicator for the extent of chemical modification. It can be clearly seen in the blow-up plot that the intensity for the $\mathrm{C}$-O characteristic peak increased as the treatment time became longer, confirming the positive relationship between the extent of filter oxidation and the corona treatment time.

There was a slight decrease in the filter pore size as a result of the corona treatment (Figure 11), possibly due to an increased roughness as a result of the corona treatment. The filtration efficiency in theory should improve with decreasing filter pore size according to the aforementioned study on the effect of filter thickness. However, opposite test results were obtained: as the corona treatment time increased from 0 to 60 seconds (Table 5), although the 
pressure drop was reduced from 0.7 to $0.2 \mathrm{psi}$, the water concentration in the effluent liquids significantly increased from $(3.7 \pm 0.3) \times 10^{2}$ to $(11.4 \pm 1.2) \times 10^{2} \mathrm{ppm}$. A probable reason for this poor filtration efficiency of the treated filter is that a super hydrophilic filter media lacks the ability to block water, and tends to allow easier water permeation through filter. While the corona-treated filter absorbed a large amount of water droplets, it could be too hydrophilic to allow for effective water release and continuous water removal from the fuel flow. This limitation in water removal due to excessive filter hydrophilicity has been discovered from the poor filtration performance of cellulosic-fiber-filters, as cellulose is a highly hydrophilic material. Nowadays, the commercial cellulose-based fuel filters are commonly silicone-treated to be more hydrophobic. [3] It is conceivable that with even more hydrophobic materials, water droplets may be easier to deform into elongated shapes and penetrate the filter due to the extremely low traction between water and fibers, and therefore may result in limited filtration efficiency. This phenomenon is to be investigated. In summary, while the high hydrophilicity could facilitate the catching of water droplets due to its affinity with water, a relatively more hydrophobic material, with a contact angle of $124^{\circ}$ in this study, is advantageous in water droplet coalescence and run-off, and therefore performs better in fuel filtration. In addition, like existing commercial materials the co-extruded exfoliated filters exhibited adjustable surface energy as a result of corona treatment, and potentially other surface treatments.

\section{Filtration mechanism: Water droplet catching, coalescence, and release}

The often neglected water droplet run-off behavior is studied to evaluate the filter's capability of releasing the captured water droplets and allowing for continuous filtration. It is well known that small water droplets tend to adhere to a fibrous media that has some surface roughness. Tilting the filter media from a horizontal position facilitates the droplet to roll and run-off. However, the small area of filter media interacting with a water droplet may be randomly oriented, representing a tilted media with a tilting angle ranging from 0 to $90^{\circ}$. Therefore, more important to effective water release is that the droplet has to reach a critical size to roll on and migrate away from a tilted filter. This critical droplet volume at instability, where the droplet starts to run off, was found to correlate with the tilting angle of the filter plane as described in Equation (5). [26]

$$
\sin \alpha=K V^{-2 / 3}
$$


Whereas $\alpha$ and $\mathrm{V}$ are the angle of inclination of the plane and the volume of the water droplet, respectively. $K=\frac{\cos \theta_{R}-\cos \theta_{A}}{C\left(\frac{d g}{\gamma}\right)}$, and $\mathrm{K}$ is a constant determined by the droplet advancing and receding contact angles $\left(\theta_{R}\right.$ and $\left.\theta_{A}\right)$, the droplet shape factor $\mathrm{C}$, the liquid density $\mathrm{d}$, the gravitational acceleration $\mathrm{g}$, and the liquid surface tension $\gamma$.

As shown in Figure 12 (a)-(e) and listed in Table 6, as the water droplet volume increased, the corresponding tilting angle of the untreated PP/PA6 filter at droplet instability was continuously decreasing. A direct proportionality can be established between $\sin \alpha$ and $V^{-2 / 3}$ (Figure 12, i). Linear fitting of the data points shows a slope, constant K, of 10.4 for the untreated PP/PA6 cross-plied filter media. Extrapolating this line to the limit of $\sin \alpha=1$, representing a piece of vertical filter media from which a water droplet runs off the easiest, provides the critical water droplet volume of $34 \mu \mathrm{L}$. Therefore, the smallest water droplet that could slide on and release from a PP/PA6 filter with a static water contact angle of $124^{\circ}$ should have a volume of $34 \mu \mathrm{L}$, referring to a hemispherical droplet with a diameter of $5.0 \mathrm{~mm}$, or a spherical droplet with a diameter of $4.0 \mathrm{~mm}$. Any smaller droplets have to accumulated and coalesce until this critical volume is reached. In comparison, as shown in Figure 12 (f)-(h), the same PP/PA6 filter that was corona-treated for 60 s needed to be tilted to a larger angle to release a water droplet with the same volume. Concluded from the linear relationship between the volume at instability and the filter tilting angle, the smallest water droplet volume for droplet run-off from this 60s-treated filter is 61 $\mu \mathrm{L}$, larger than the value for an untreated filter. Therefore, it is more difficult for water droplets to release from a very hydrophilic filter: they have to grow to $61 \mu \mathrm{L}$ instead of $34 \mu \mathrm{L}$ before removal. This advantage of a more hydrophobic filter is in accordance with the study on filter hydrophilicity.

In general, the whole process of water droplet filtration from fuel can be divided into three steps: droplet capture, coalescence/droplet growth, and droplet run-off/release. As described in the previous sections, for a fuel/water mixture having a distribution of water droplet sizes, the big water drops can be blocked and held at the microscale pores. The size of this drop is enlarged when subsequent droplets hit and coalesce with it, and finally the drop is released from the bottom of the filter due to its higher density than fuel when the drop size reaches the critical volume at instability. If the initial water droplet size is smaller than the filter pore size, it is possible for the droplet to travel through the filter pores, which results in an incomplete fuel filtration; or to be captured by the fibers, where a high filter surface area is highly desirable. After droplet coalescence above the 
instability point, these captured drops tend to roll on and move away from the filter. Although higher hydrophilicity could facilitate water droplet catching, the droplets can penetrate the filter more easily due to the filter's affinity to water.

The co-extruded PP/PA6 fibrous filter has microscale pore sizes that can block large water droplets in the droplet capturing step, superior surface area for catching the smaller droplets, and a hydrophobic nature that assists water droplet removal. Because of these advantages, the PP/PA6 fibrous filters have large potential as fuel filter media.

\section{Conclusions}

Fibrous filters comprised of polypropylene (PP) / polyamide 6 (PA6) micro-/nano-fibers have been produced using a melt-based technology. The processing-structure-filtration property relationships have been investigated for the removal of water droplets from diesel fuel. In comparison with a commercial fuel filter, the PP/PA6 fibrous filter has smaller mean pore size, much higher surface area, tougher mechanical behavior, and much higher water droplet filtration efficiency at the same pressure drop. It has been found out that increasing the filter thickness reduces the filter pore size but does not influence the porosity. As a result, the filtration efficiency of water in diesel is improves as the filter blocks more water droplets. Filter surfaces exposed to corona treatment produced porous separators with more hydrophilic surfaces, however, the change in surface energy ultimately reduced the filtration efficiency due to limitations on water droplet run off from the filter. The flexibility of processing and tuning both the mechanical and chemical PP/PA6 porous fiber separator films to described fuel/water filter performance targets were demonstrated. A conclusion of an ideal PP/PA6 porous separator candidate for fuel filtration with small pore sizes, around 10 microns in average, larger surface area for droplet capture, high porosity, greater than $85 \%$, and a hydrophobic nature for successful droplet release have been demonstrated in a new, scalable, low cost manufacturing process.

\section{Acknowledgments}

The project was made possible through the generous financial and technical support of the National Science Foundation Science and Technology Center, Center for Layered Polymeric Systems (DMR-0423914). We would also like to thank our collaborator, PolymerPlus, LLC, and the National Science Foundation Small Business Technology Transfer (NSF STTR) for their financial support (award \# 1346309). 


\section{References}

[1] Baldwin Filters, Inc., Diesel fuel filter/water separators, 2014, Retrieved from: http://www.baldwinfilter.com/literature/english/6\%20dahl/Form4005.pdf, accessed on Nov. $1^{\text {st }}$, 2016.

[2] C. Shin, G.G. Chase, Water-in-oil coalescence in micro-nanofiber composite filters, AIChE Journal, 50 (2004) 343-350.

[3] Donaldson Company, Inc., SynteqTM Media Technology for Fuel Filtration, 2009, Retrieved from: https://www.donaldson.com/content/dam/donaldson/engine-hydraulicsbulk/literature/north-america/engine-liquid/Fuel/F111138-ENG/Synteq-Media-for-FuelFiltration.pdf, accessed on Nov. ${ }^{\text {st }}, 2016$.

[4] R. Kotra, H. Rong, Melt blown technology, 2004, Retrieved from:

http://www.engr.utk.edu/mse/pages/Textiles/Melt\%20Blown\%20Technology.htm, accessed on Nov. $1^{\text {st }}, 2016$.

[5] J. Wang, D. Langhe, M. Ponting, G.E. Wnek, L.T.J. Korley, E. Baer, Manufacturing of polymer continuous nanofibers using a novel co-extrusion and multiplication technique, Polymer, 55 (2014) 673-685.

[6] E. Baer, D. Langhe, J. Wang, WO2013155519 A1, Production of micro- and nano-fibers by continuous microlayer coextrusion, 2013.

[7] J. Wang, R. Ayyar, A. Olah, E. Baer, Processing-structure-property relationships of novel fibrous filters produced by a melt-process, Journal of Materials Science, 51 (2016) 188-203. [8] S.S. Voyutskii, K.A. Kal'yanova, R. Panick, N. Fodiman, Mechanism of separation of the dispersed phase of emulsion during filtration, Chemical Abstract, 49 (1955).

[9] G. Chase, P. Kulkarni, US20100200512 A1, Mixed hydrophilic/hydrophobic fiber media for liquid-liquid coalescence, University of Akron, 2010.

[10] C. Shin, G.G. Chase, D.H. Reneker, The effect of nanofibers on liquid-liquid coalescence filter performance, AIChE Journal, 51 (2005) 3109-3113.

[11] P.S. Kulkarni, S.U. Patel, S.U. Patel, G.G. Chase, Coalescence filtration performance of blended microglass and electrospun polypropylene fiber filter media, Separation and Purification Technology, 124 (2014) 1-8.

[12] P.S. Kulkarni, S.U. Patel, G.G. Chase, Layered hydrophilic/hydrophobic fiber media for water-in-oil coalescence, Separation and Purification Technology, 85 (2012) 157-164.

[13] R.N. Hazlett, Fibrous Bed Coalescence of Water. Role of a Sulfonate Surfactant in the Coalescence Process, Industrial \& Engineering Chemistry Fundamentals, 8 (1969) 633-640. [14] R.N. Hazlett, Fibrous Bed Coalescence of Water. Steps in the Coalescence Process, Industrial \& Engineering Chemistry Fundamentals, 8 (1969) 625-632.

[15] S.U. Patel, S.U. Patel, G.G. Chase, Electrospun Superhydrophobic Poly(vinylidene fluorideco-hexafluoropropylene) Fibrous Membranes for the Separation of Dispersed Water from Ultralow Sulfur Diesel, Energy \& Fuels, 27 (2013) 2458-2464. 
[16] G. Viswanadam, G.G. Chase, Water-diesel secondary dispersion separation using superhydrophobic tubes of nanofibers, Separation and Purification Technology, 104 (2013) 8188.

[17] S.U. Patel, G.G. Chase, Separation of water droplets from water-in-diesel dispersion using superhydrophobic polypropylene fibrous membranes, Separation and Purification Technology, 126 (2014) 62-68.

[18] F. Ejaz Ahmed, B.S. Lalia, N. Hilal, R. Hashaikeh, Underwater superoleophobic cellulose/electrospun PVDF-HFP membranes for efficient oil/water separation, Desalination, 344 (2014) 48-54.

[19] E.J. Clayfield, A.G. Dixon, A.W. Foulds, R.J.L. Miller, The coalescence of secondary dispersions, Journal of Colloid and Interface Science, 104 (1985) 500-511.

[20] R.N. Hazlett, Fibrous bed coalescence of water, Industrial \& Engineering Chemistry Fundamentals, 8 (1969) 625-632.

[21] A. Krasinski, A numerical model of droplets coalescence and drainage in fibrous structures, Chemical Engineering Transactions, 32 (2013) 1495-1500.

[22] M.S. Ellison, P.E. Lopes, W.T. Pennington, In-situ X-ray characterization of fiber structure during melt spinning, Journal of Engineered Fibers and Fabrics, 3 (2008) 12.

[23] M.-R. Huang, X.-G. Li, B.-R. Fang, $\beta$-nucleators and $\beta$-crystalline form of isotactic polypropylene, Journal of Applied Polymer Science, 56 (1995) 1323-1337.

[24] S. Ran, X. Zong, D. Fang, B.S. Hsiao, B. Chu, R.A. Phillips, Structural and Morphological Studies of Isotactic Polypropylene Fibers during Heat/Draw Deformation by in-Situ Synchrotron SAXS/WAXD, Macromolecules, 34 (2001) 2569-2578.

[25] R.F. Stepaniak, A. Garton, D.J. Carlsson, D.M. Wiles, The characterization of nylon 6 filaments by x-ray diffraction, Journal of Applied Polymer Science, 23 (1979) 1747-1757.

[26] E. Baer, T.F. McLaughlin, The determination of surface properties of polymers form liquid drop stability on an inclined plane, Journal of Applied Polymer Science, V (1961) 6. 


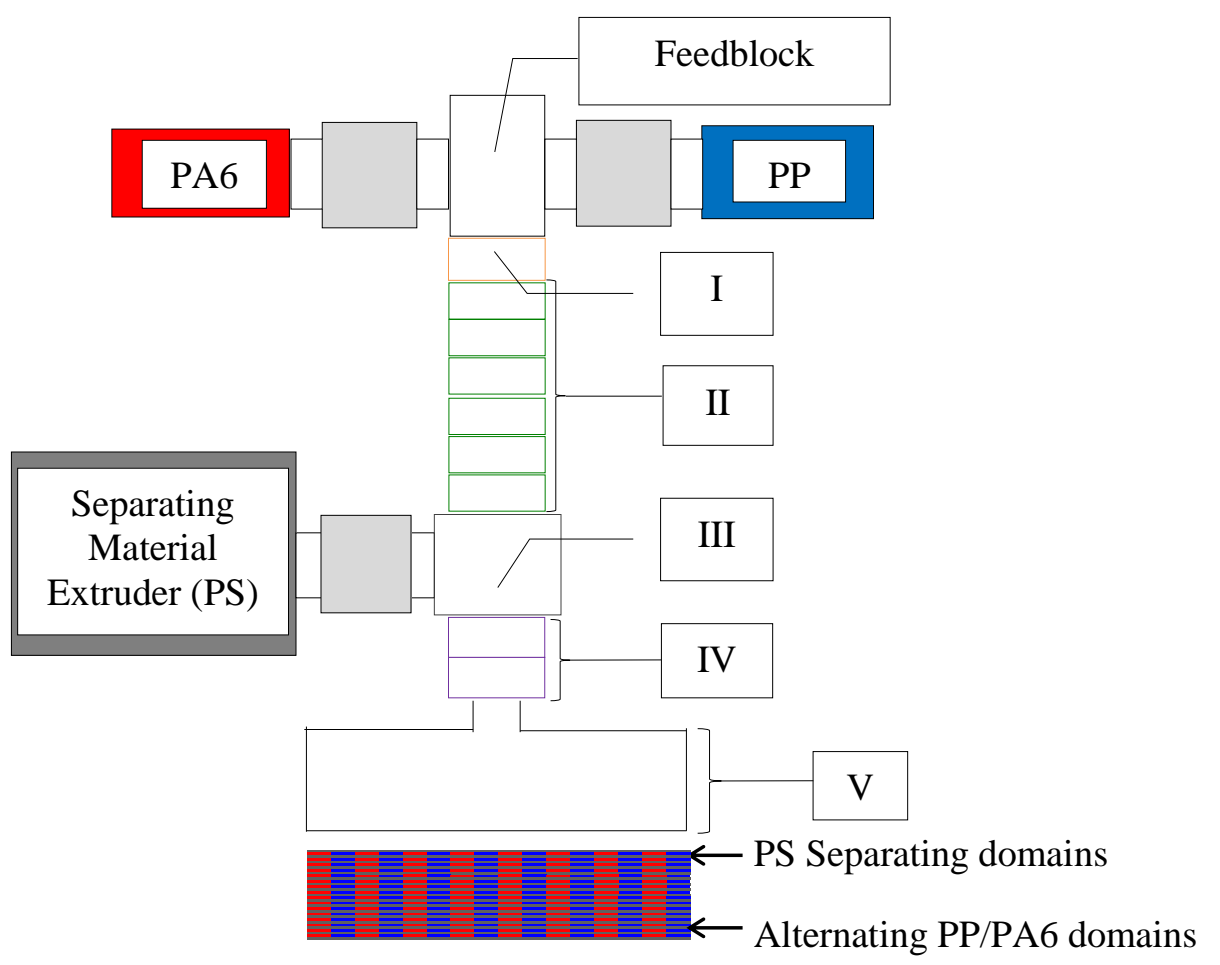

Cross section of the extruded tape

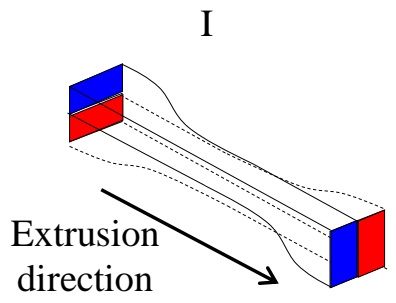

III

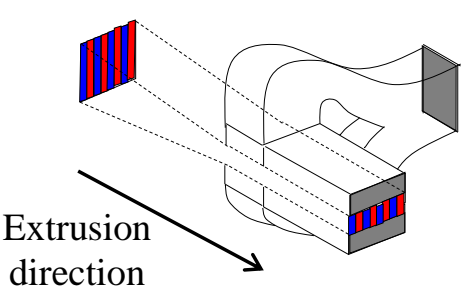

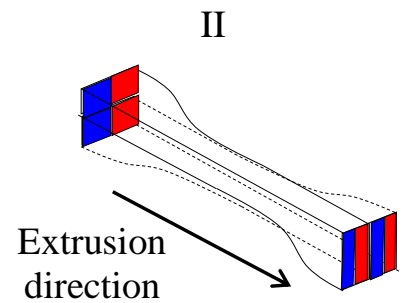

IV

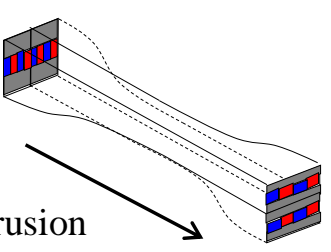

direction

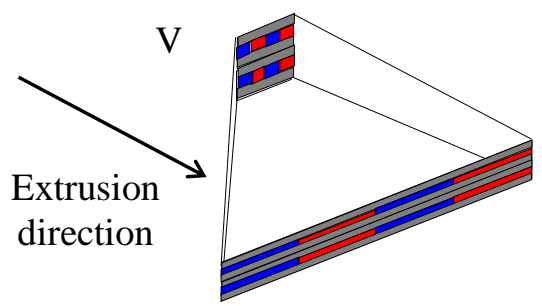

Figure 1. Extrusion line containing five essential steps for production of the PP/PA6/PS composite tapes 


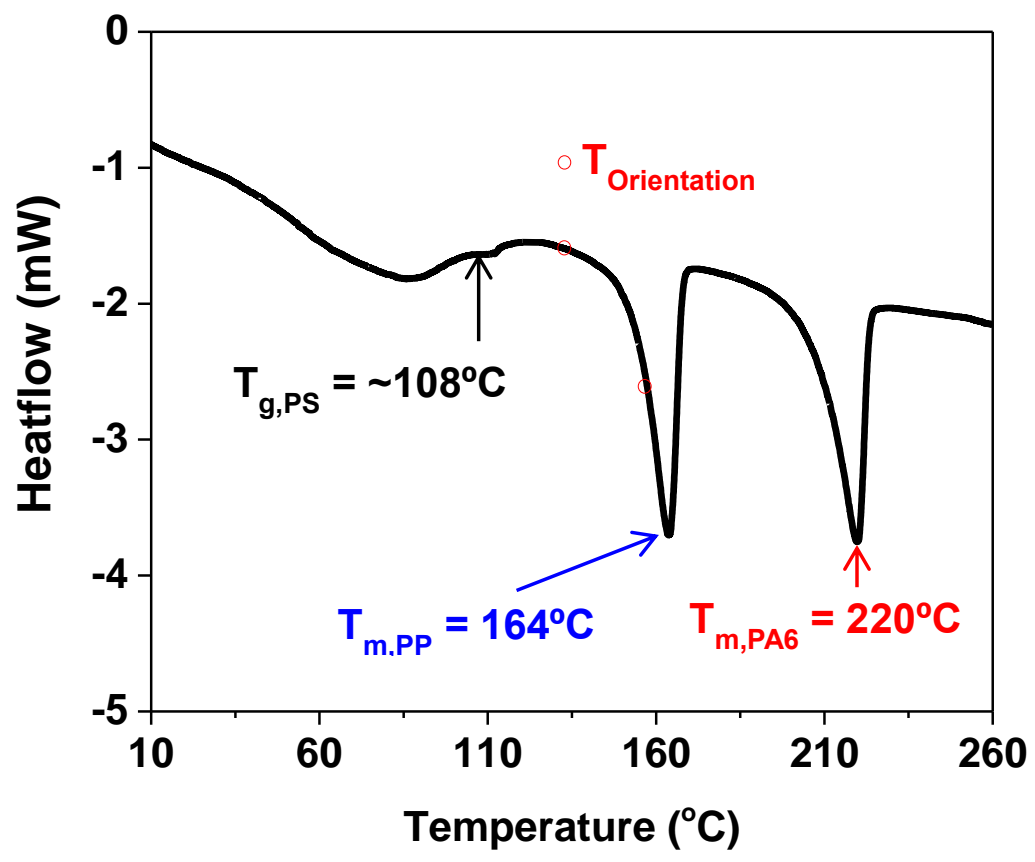

(a)

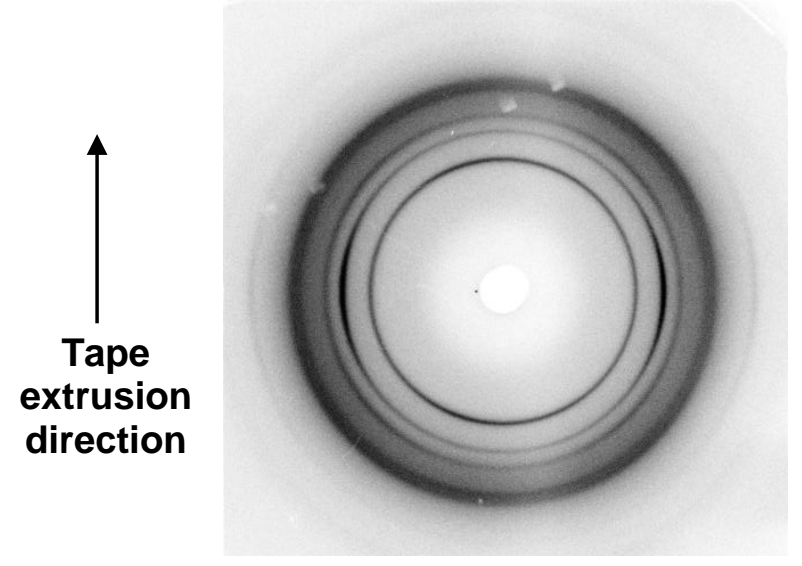

(b)

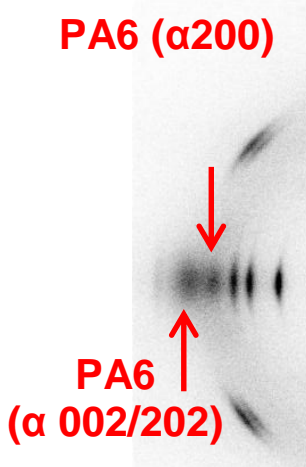

(c)

Figure 2. (a) Thermograph for the PP/PA6/PS composite tape containing 8192x32 PP/PA6 domains and $9 \%$ PS separating domain. The orientation temperatures are denoted in the graph as 130 and $155^{\circ} \mathrm{C}$. The WAXD patterns for (b) the as-extruded and (c) oriented tape with draw ratio of $4.5 x$. 


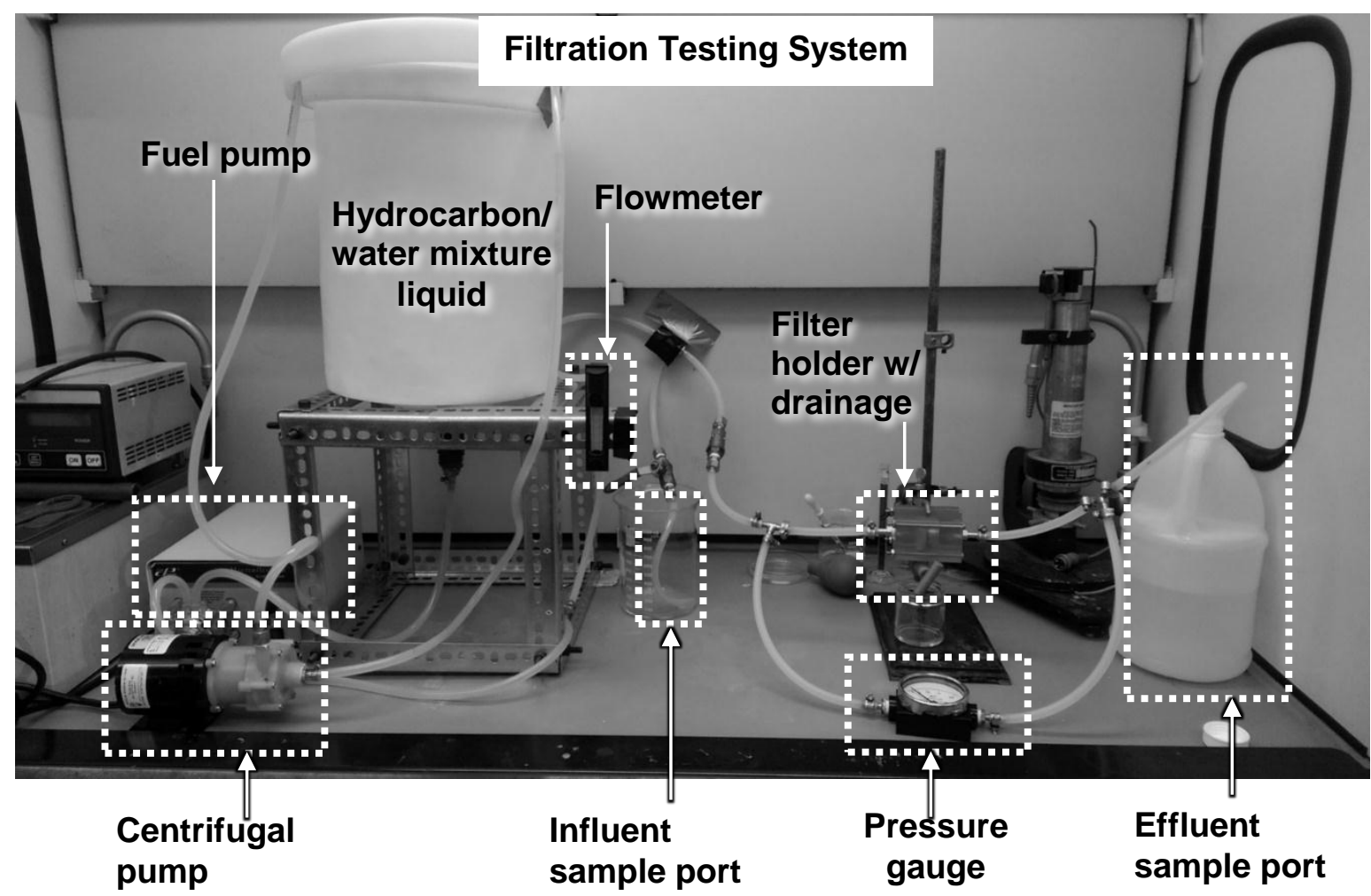

Figure 3. Fuel filtration testing set-up and its components. 


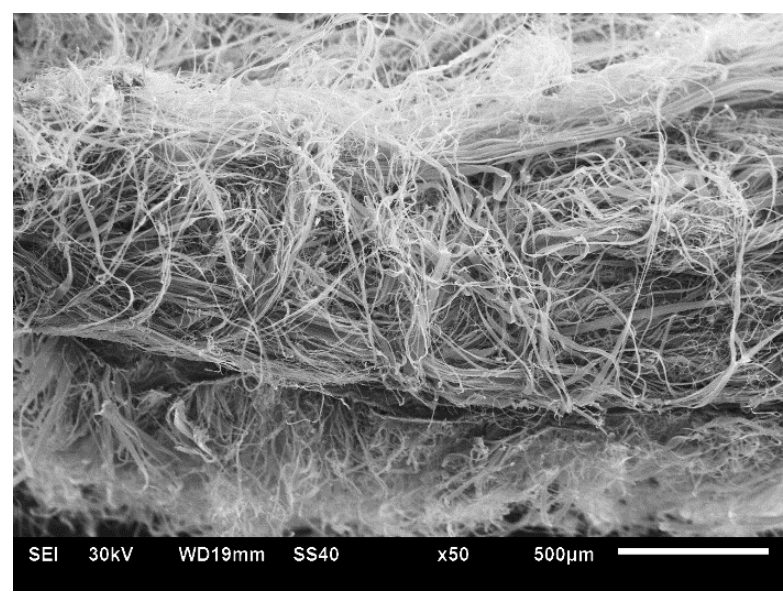

(a)

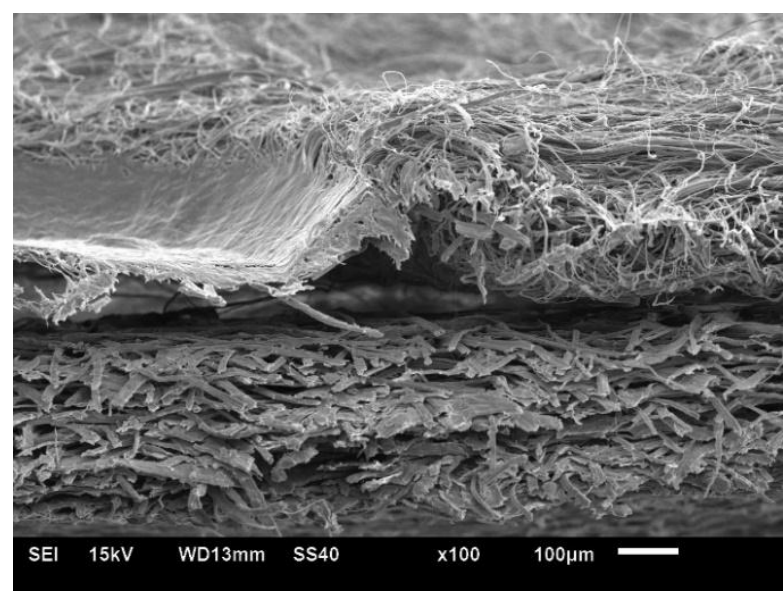

(c)

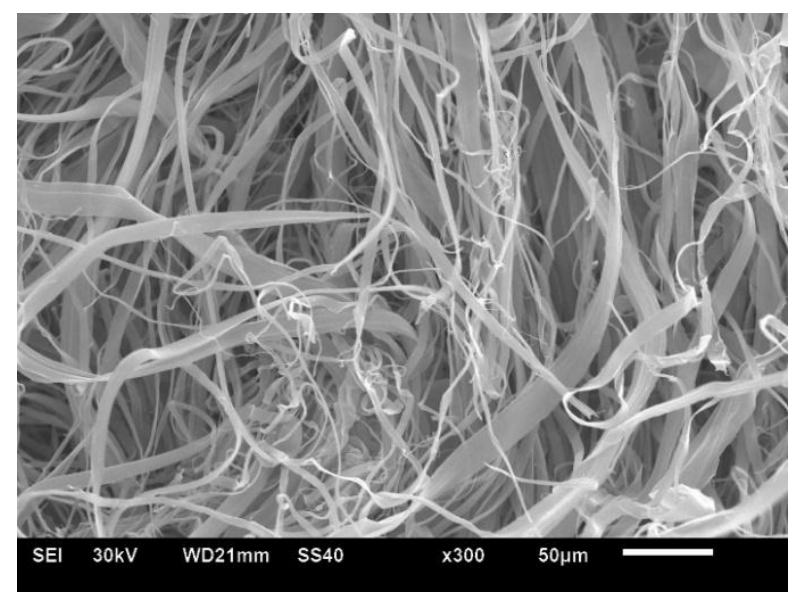

(b)

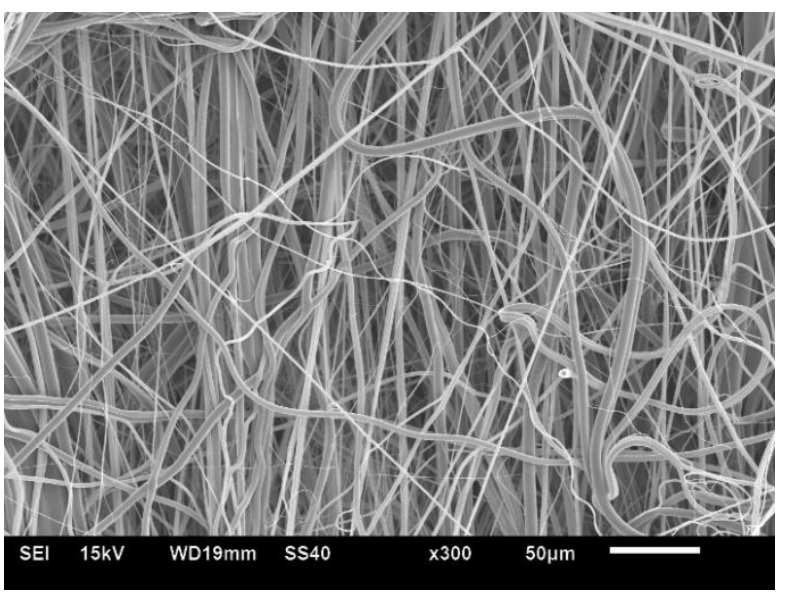

(d)

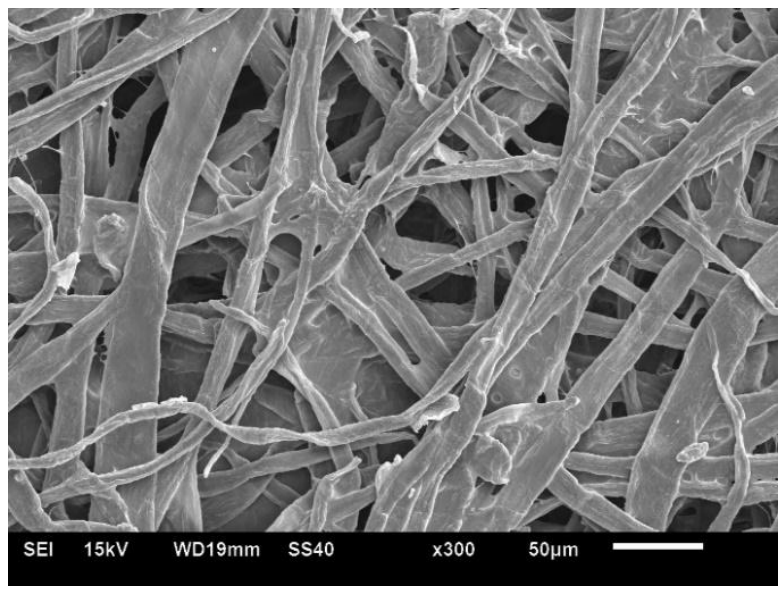

(e)

Figure 4. SEM images of (a) the cross-section and (b) the surface of the PP/PA6 fiber filters made from tapes with a draw ratio of 4.5x; SEM images of (c) the cross-section, (d) top layer surface, and (e) bottom layer surface for the commercial filter. 


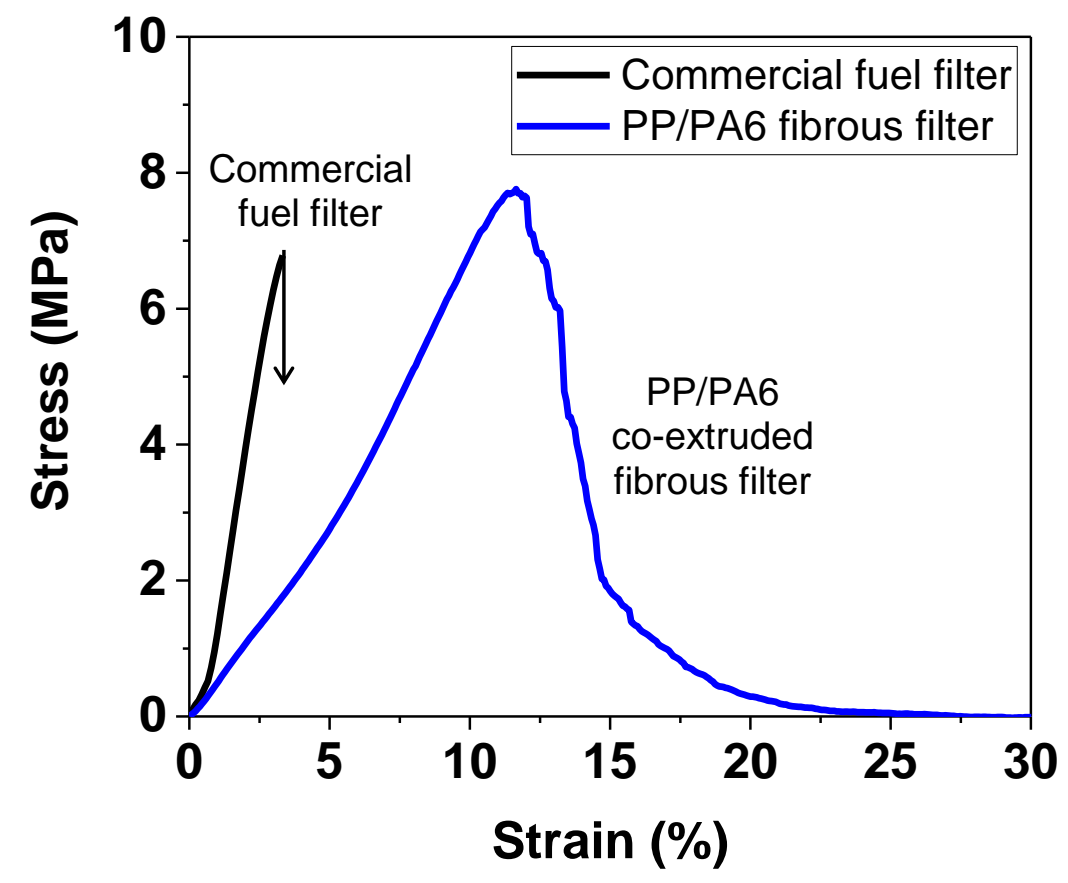

Figure 5. Mechanical properties for the commercial fuel filter and the PP/PA6 fibrous filter produced from tapes with a draw ratio of $4.5 \mathrm{x}$. 


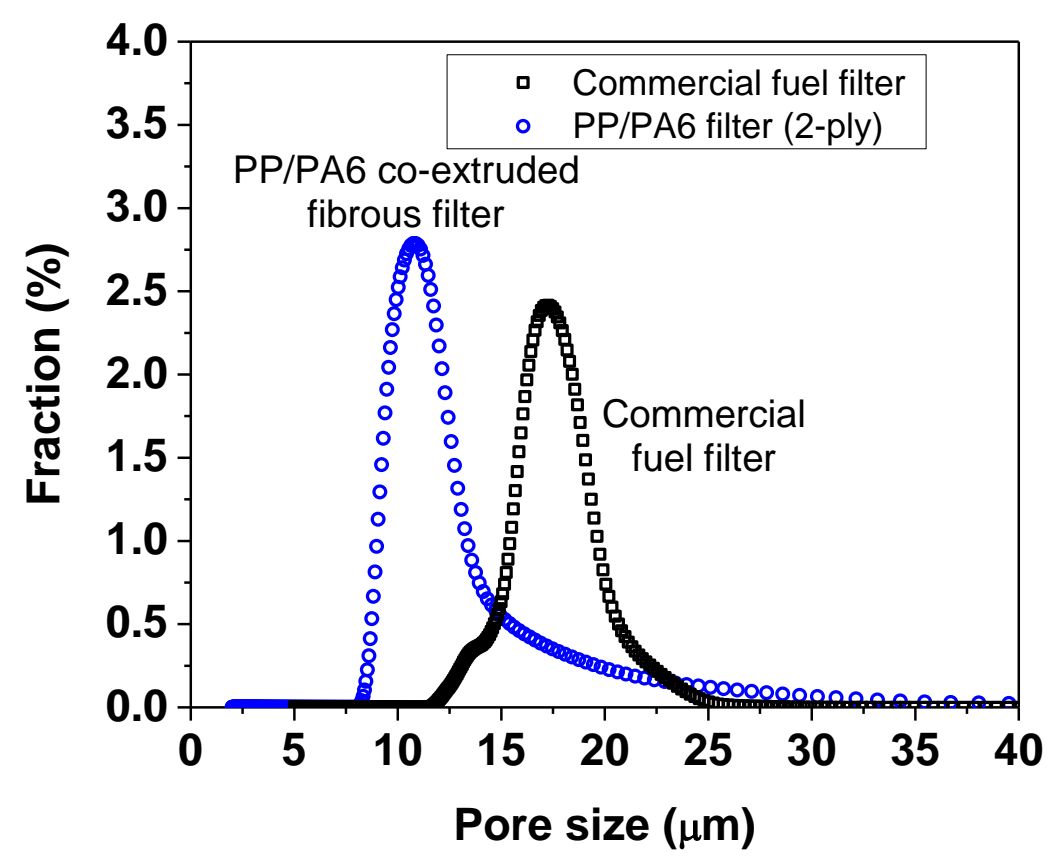

Figure 6. Pore size distribution for the commercial fuel filter and the PP/PA6 2-layered coextruded fibrous filter 


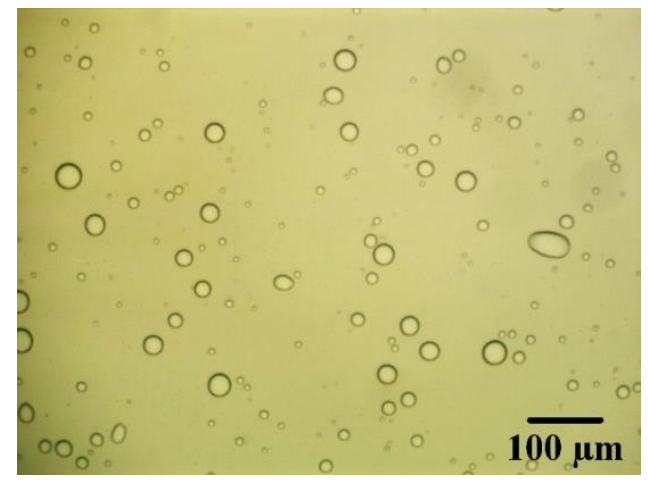

(a)

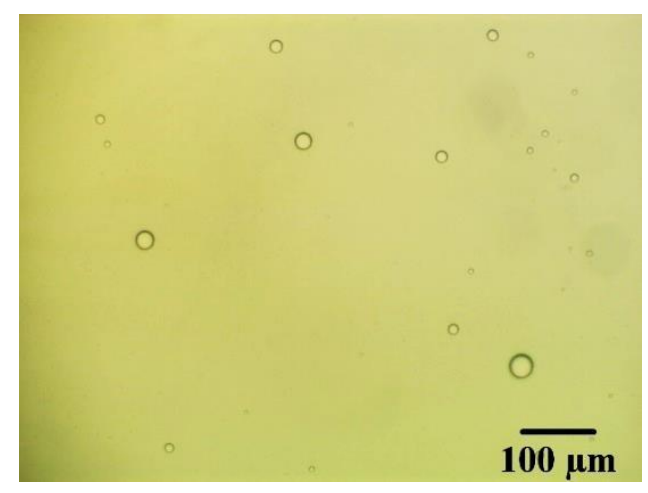

(c)

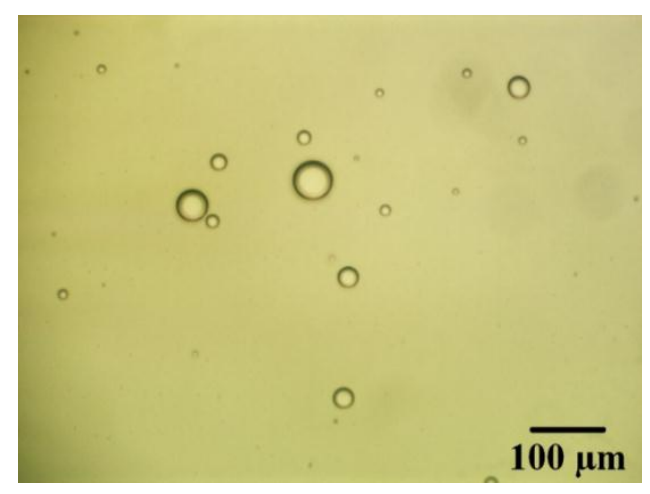

(e)

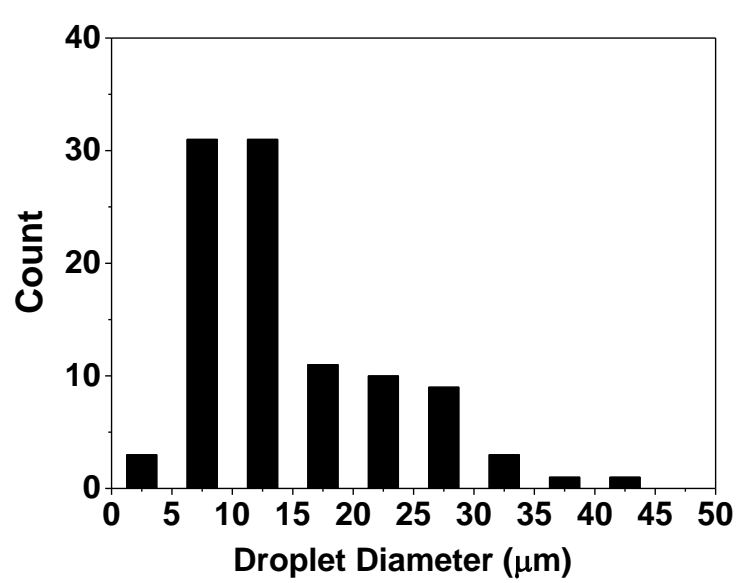

(b)

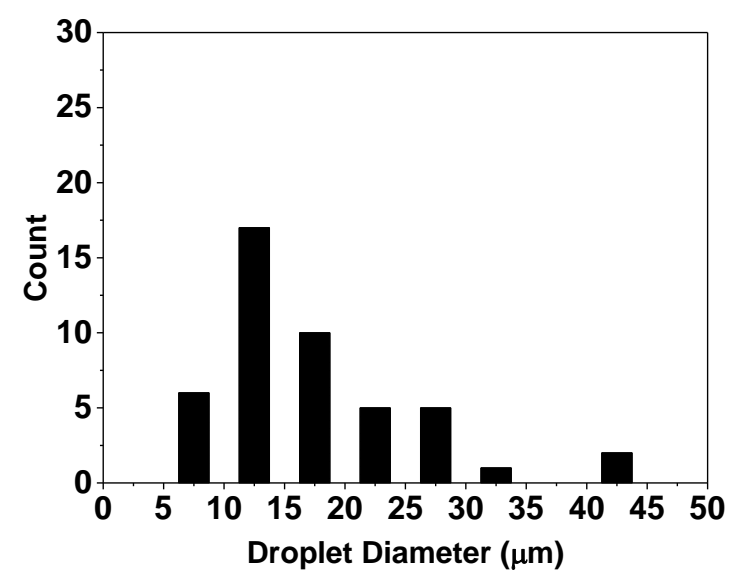

(d)

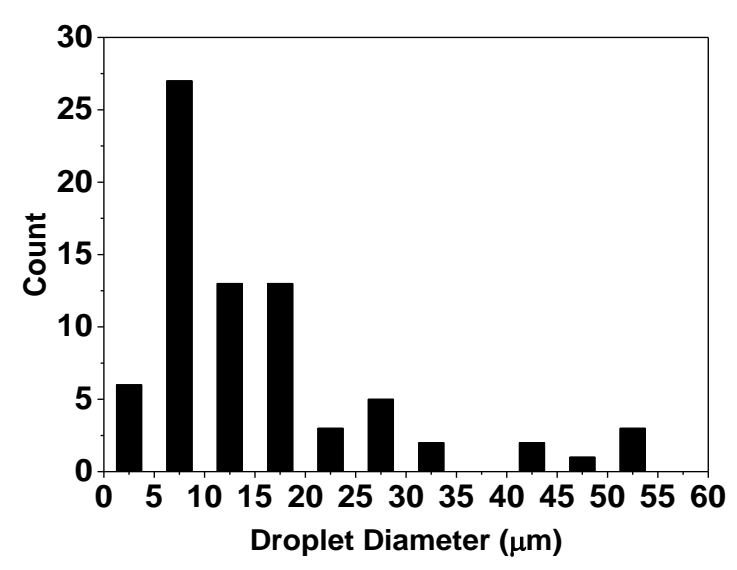

(f)

Figure 7. (a) Optical Microscopy image and (b) droplet size count for the upstream/influent emulsified fuel/water mixture containing microscale water droplets. (c) Optical Microscopy image and (d) droplet size count for the effluent fuel/water emulsified mixture after filtration using the PP/PA6 filter. (e) Optical Microscopy image and (f) droplet size count for the effluent fuel/water emulsified mixture after filtration using the commercial filter. 


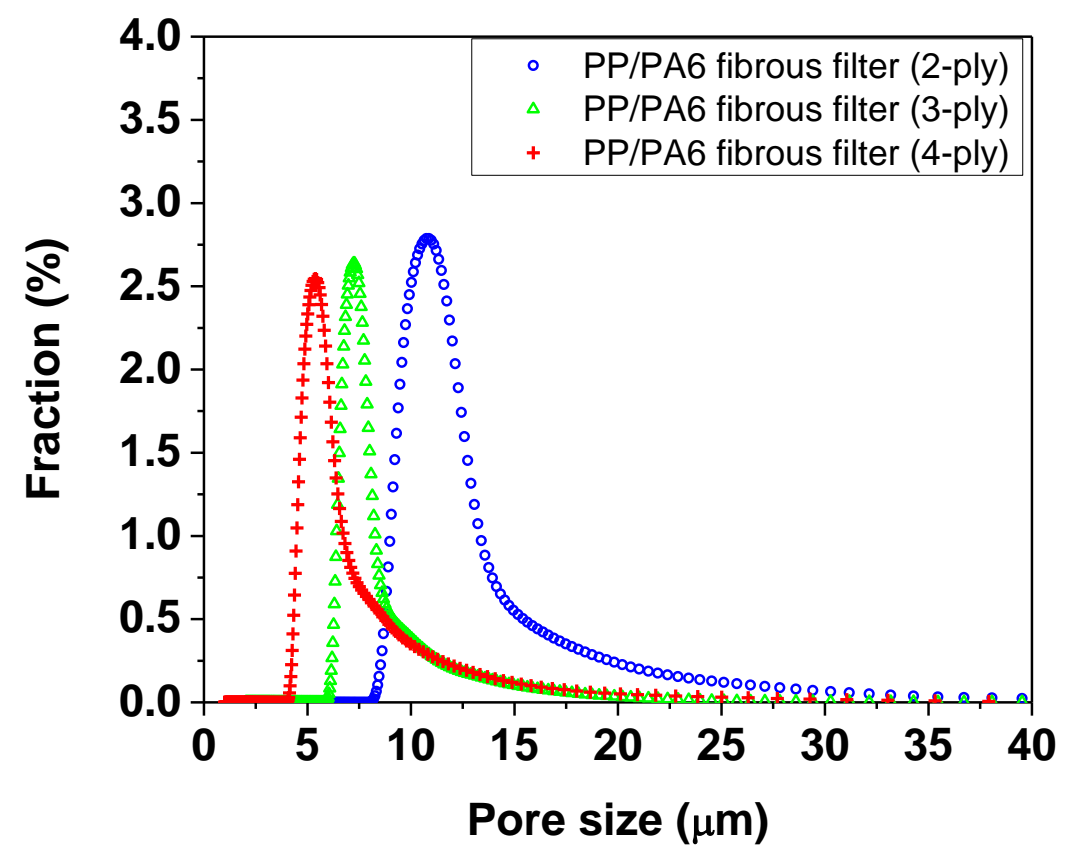

Figure 8. Pore size distribution of the PP/PA6 filters comprised of 2 plies, 3 plies, and 4 plies. 


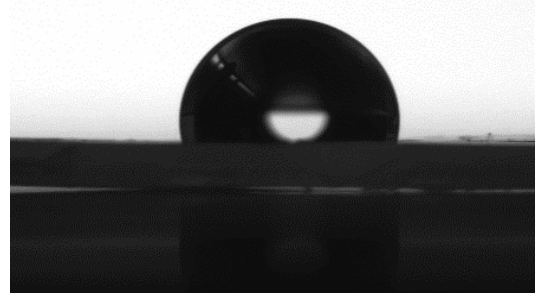

(a)

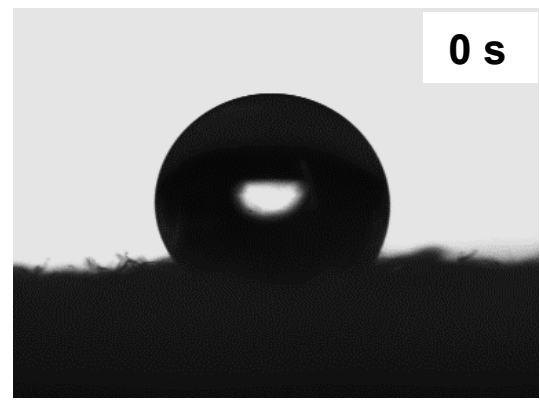

(d)

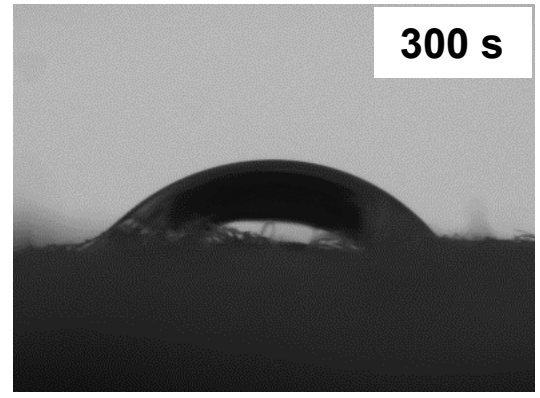

(g)

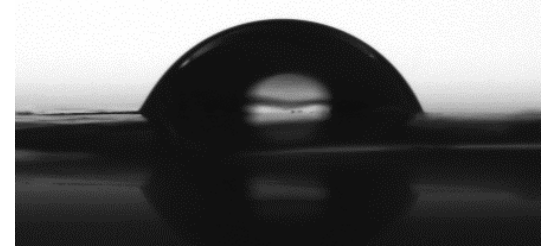

(b)

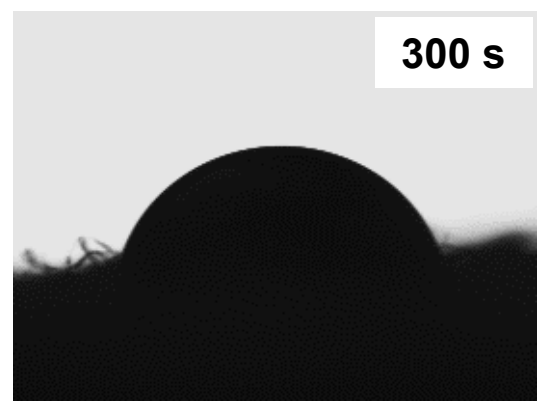

(e)

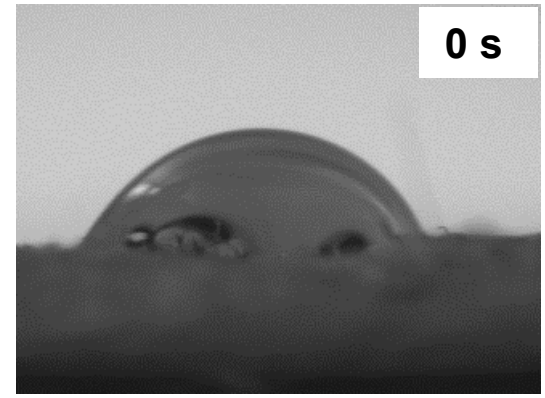

(h)

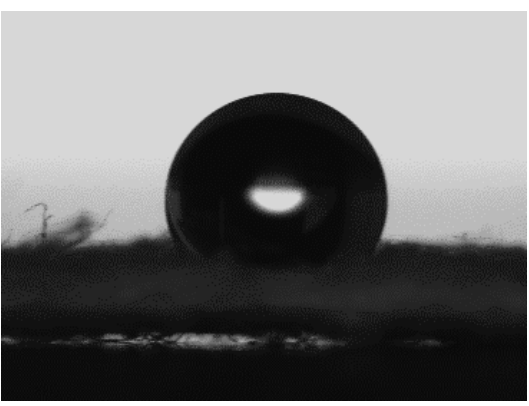

(c)

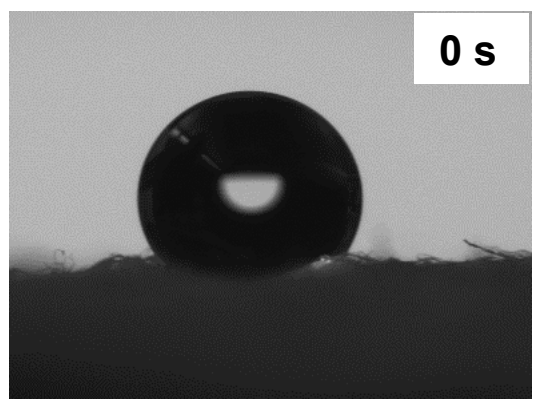

(f)

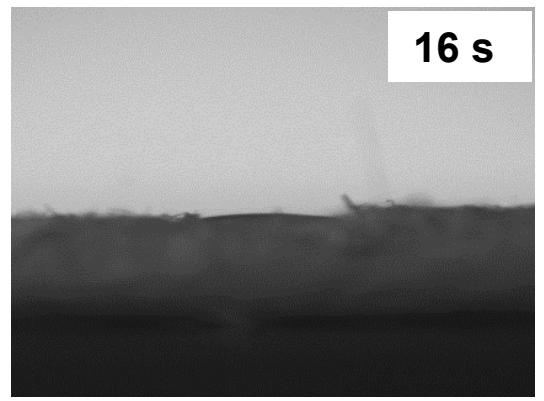

(i)

Figure 9. Water contact angles for (a) PP film, (b) PA6 film, (c) the un-treated PP/PA6 fibrous filter, and the corona-treated PP/PA6 fibrous filters: (d) tested immediately after treatment for $10 \mathrm{~s}$, (e) tested at $300 \mathrm{~s}$ after treatment for $10 \mathrm{~s}$, (f) tested immediately after treatment for $30 \mathrm{~s}$, (g) tested at $300 \mathrm{~s}$ after treatment for $30 \mathrm{~s}$, (h) tested immediately after treatment for $60 \mathrm{~s}$, and (i) tested at $16 \mathrm{~s}$ after treatment for $60 \mathrm{~s}$. 


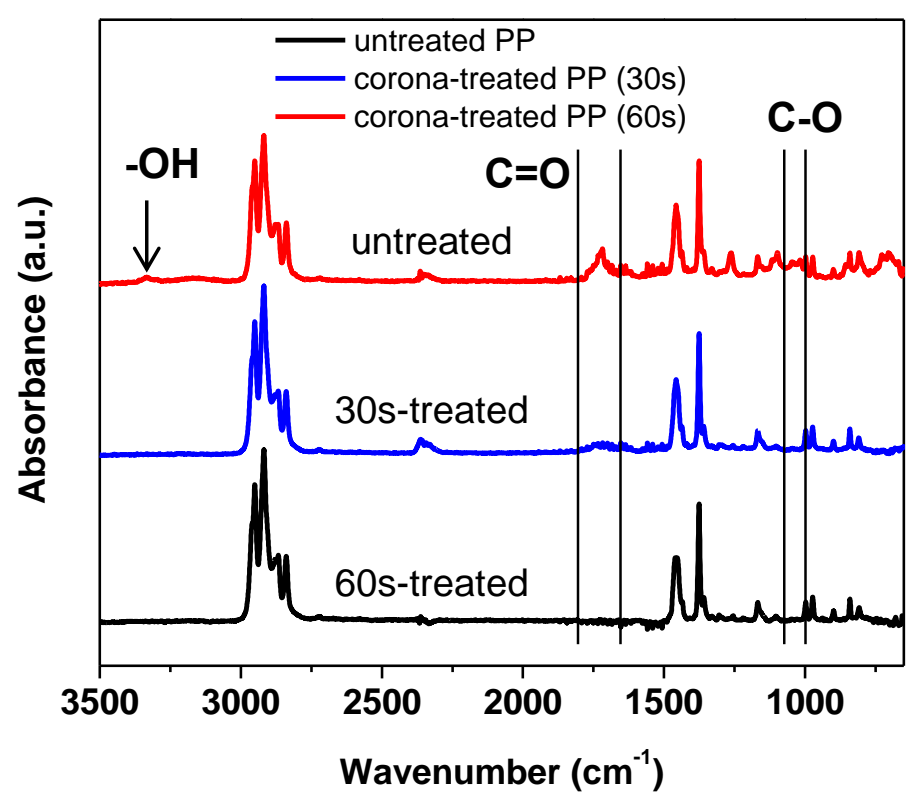

(a)

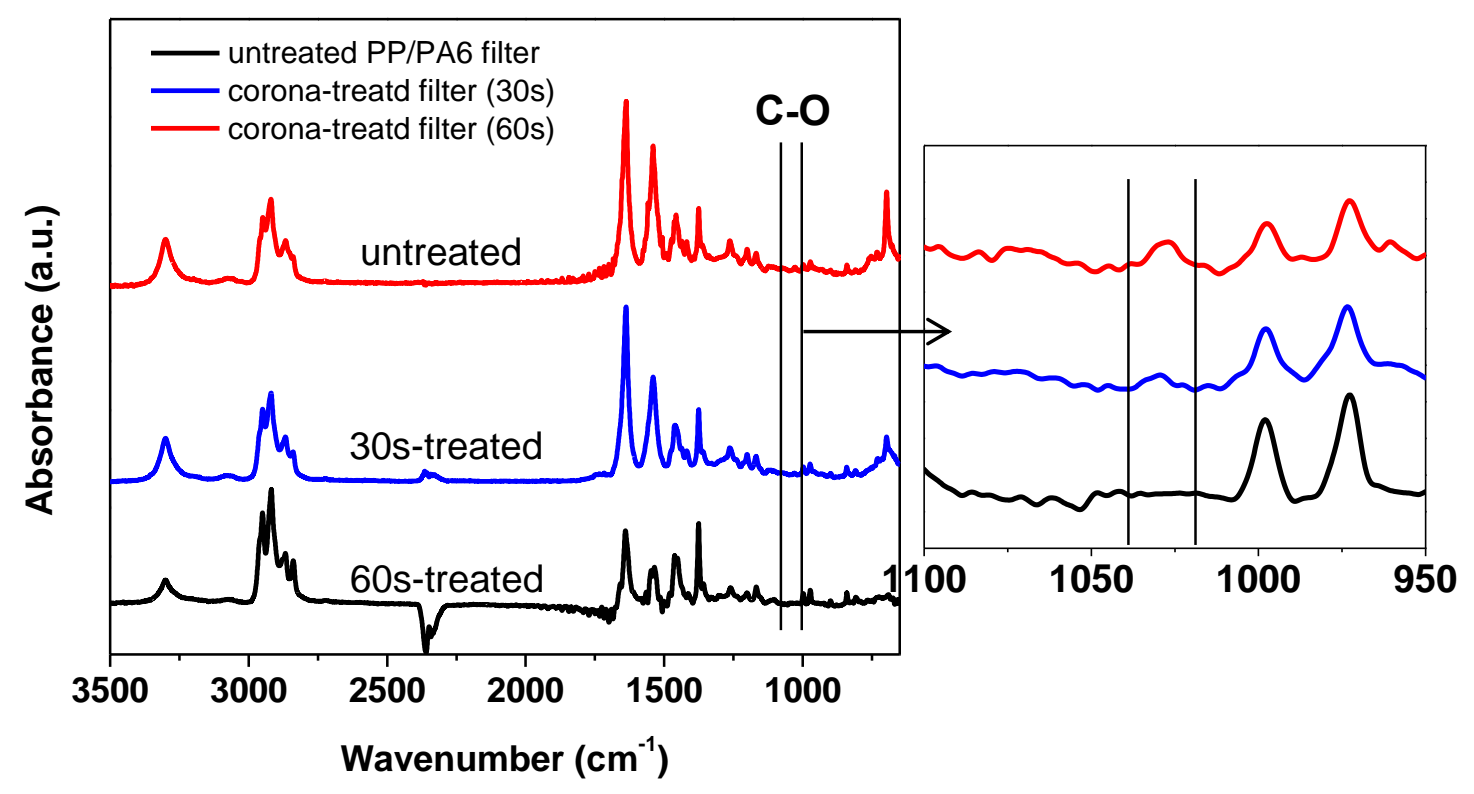

(b)

Figure 10. (a) FTIR/ATR absorption of the un-treated and corona-treated PP films for 30s and 60s. (b) FTIR/ATR absorption of the un-treated and corona-treated PP/PA6 fibrous filters for $30 \mathrm{~s}$ and $60 \mathrm{~s}$. 


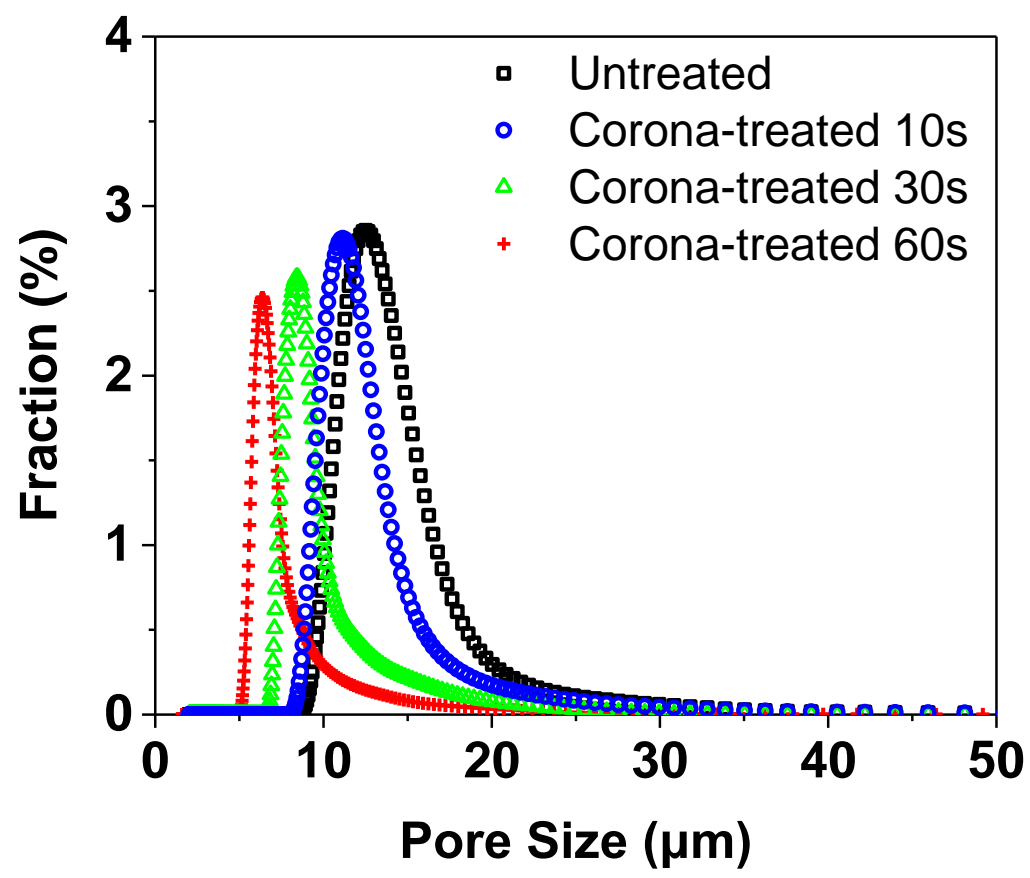

Figure 11. Pore size distribution for the PP/PA6 fibrous filters with different extent of corona treatment: $0,10,30$, and $60 \mathrm{~s}$. 


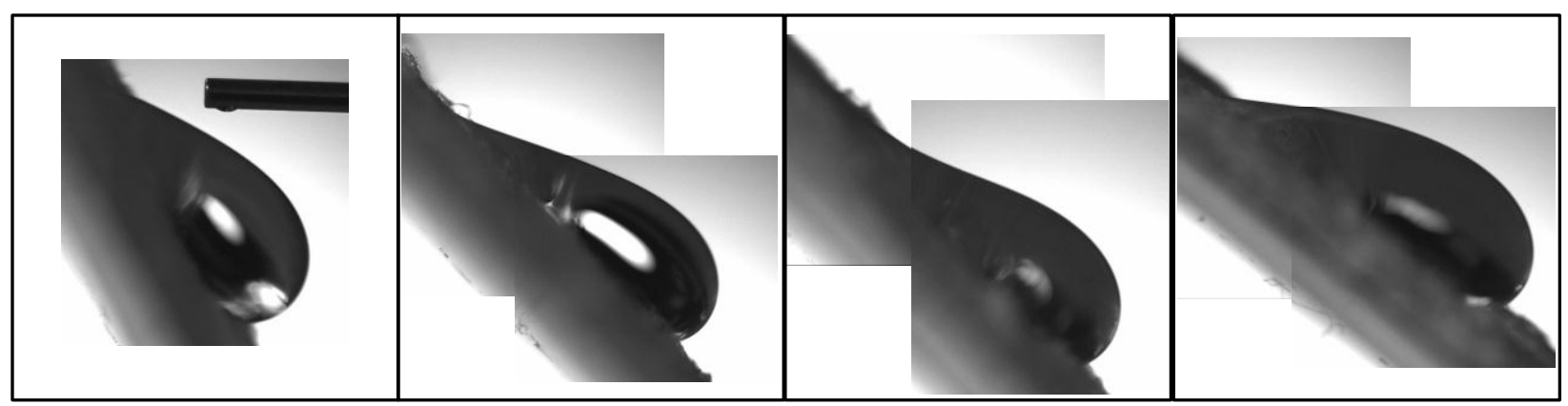

(a)

(b)

(c)

(d)

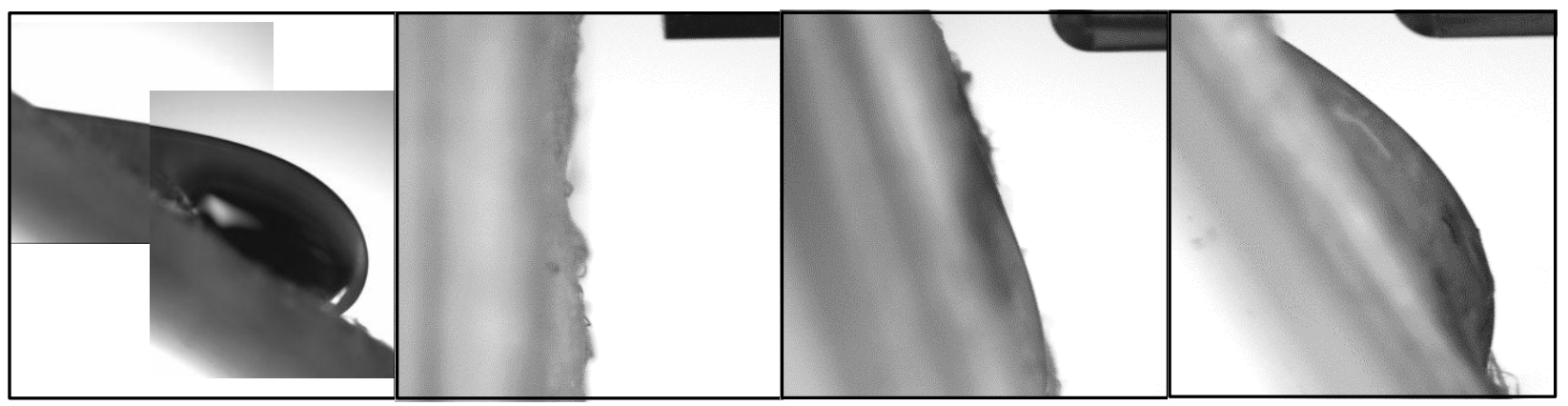

(e)

(f)

(g)

(h)

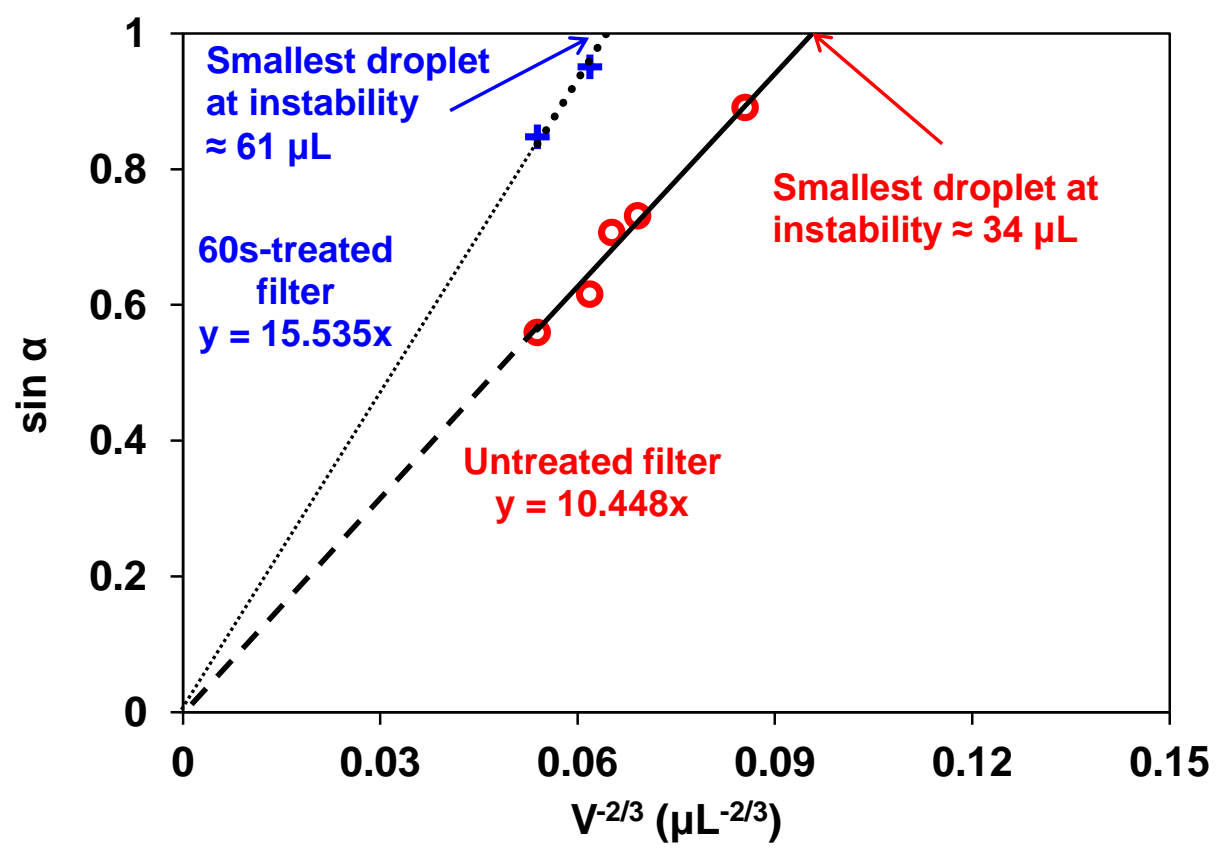

(i)

Figure 12. Droplet on a tilted untreated PP/PA6 fibrous filter at instability with the droplet volumes of (a) $40 \mu \mathrm{L}$, (b) $55 \mu \mathrm{L}$, (c) $60 \mu \mathrm{L}$, (d) $65 \mu \mathrm{L}$, and (e) $80 \mu \mathrm{L}$. Droplet on a tilted 60streated PP/PA6 fibrous filter at instability with the droplet volumes of (f) $60 \mu \mathrm{L},(\mathrm{g}) 65 \mu \mathrm{L}$, and (h) $80 \mu \mathrm{L}$. (i) Correlation of the tilting angle and the droplet volume for the untreated and 60streated filters. 
Table 1. Materials and their properties

\begin{tabular}{cccc}
\hline Material & Density $\left(\mathrm{g} / \mathrm{cm}^{3}\right)^{\mathrm{a}}$ & Transition Temperature $(\mathrm{s})$ & Water Contact Angle $\left(^{\circ}\right)$ \\
\hline PP & 0.90 & $\mathrm{~T}_{\mathrm{g}}=0{ }^{\circ} \mathrm{C}, \quad \mathrm{T}_{\mathrm{m}}=164{ }^{\circ} \mathrm{C}$ & 103 \\
\hline PA6 & 1.13 & $\mathrm{~T}_{\mathrm{g}}=\sim 47{ }^{\circ} \mathrm{C}, \mathrm{T}_{\mathrm{m}}=220^{\circ} \mathrm{C}$ & 67 \\
\hline PS & 1.04 & $\mathrm{~T}_{\mathrm{g}}=\sim 108^{\circ} \mathrm{C}$ & Not tested \\
\hline
\end{tabular}

${ }^{a}$ provided by resin suppliers 
Table 2. Mechanical properties of the commercial fuel filter and the PP/PA6 filter produced from tapes with a draw ratio of $4.5 \mathrm{x}$

\begin{tabular}{lccc}
\hline \multicolumn{1}{c}{ Sample } & $\begin{array}{c}\text { Modulus } \\
(\mathrm{MPa})\end{array}$ & $\begin{array}{c}\text { Strength } \\
(\mathrm{MPa})\end{array}$ & $\begin{array}{c}\text { Total Energy } \\
\text { under curve } \\
\left(\mathrm{x} 10^{4} \mathrm{~J} / \mathrm{m}^{3}\right)\end{array}$ \\
\hline Commercial fuel filter & 272 & 6.8 & 10.4 \\
\hline PP/PA6 Filter (From oriented tapes, DR $=4.5)$ & 83 & 7.7 & 64.4 \\
\hline
\end{tabular}


Table 3. Comparison of the structure and filtration properties of the commercial filter and the PP/PA6 fibrous filter

\begin{tabular}{cccccccc}
\hline & $\begin{array}{c}\text { Thickness } \\
(\mathrm{mm})\end{array}$ & $\begin{array}{c}\text { Surface } \\
\text { area } \\
\left(\mathrm{m}^{2} / \mathrm{g}\right)\end{array}$ & $\begin{array}{c}\text { Pore size } \\
\text { range } \\
(\mu \mathrm{m})\end{array}$ & $\begin{array}{c}\text { Mean } \\
\text { pore size } \\
(\mu \mathrm{m})\end{array}$ & $\begin{array}{c}\text { Porosity } \\
(\%)\end{array}$ & $\begin{array}{c}\Delta \mathrm{P} \\
(\mathrm{psi})\end{array}$ & $\begin{array}{c}\text { Effluent } \\
\mathrm{C}_{\text {water }} \\
\left(\mathrm{x} 10^{2} \mathrm{ppm}\right)\end{array}$ \\
\hline $\begin{array}{c}\text { Commercial } \\
\text { fuel filter }\end{array}$ & 0.74 & $\begin{array}{c}0.23 \pm \\
0.005\end{array}$ & $12-26$ & 17 & $\sim 84^{\mathrm{a}}$ & 0.8 & $9.5 \pm 0.9$ \\
\hline $\begin{array}{c}\text { PP/PA6 } \\
\text { fibrous filter }\end{array}$ & 0.74 & $\begin{array}{c}2.92 \pm \\
0.03\end{array}$ & $8.1-49$ & 11 & 87 & 0.7 & $3.7 \pm 0.3$ \\
\hline
\end{tabular}

${ }^{\text {a }}$ Estimated from the densities of cellulose and polyethylene terephthalate 
Table 4. Structure of the 2-plied, 3-plied, and 4-plied PP/PA6 fibrous filters.

\begin{tabular}{ccccccc}
\hline Sample & $\begin{array}{c}\text { Filter } \\
\text { Thickness } \\
(\mathrm{mm})\end{array}$ & $\begin{array}{c}\text { Pore Size } \\
\text { Range }(\mu \mathrm{m})\end{array}$ & $\begin{array}{c}\text { Mean Pore } \\
\text { Size }(\mu \mathrm{m})\end{array}$ & $\begin{array}{c}\text { Porosity } \\
(\%)\end{array}$ & $\Delta \mathrm{P}(\mathrm{psi})$ & $\begin{array}{c}\text { Effluent } \\
\mathrm{C}_{\text {water }} \\
\left(\mathrm{x} 10^{2} \mathrm{ppm}\right)\end{array}$ \\
\hline $\begin{array}{l}\text { PP/PA6 2- } \\
\text { plied filter }\end{array}$ & 0.74 & $8.1-49$ & 11 & 87 & 0.7 & $3.7 \pm 0.3$ \\
\hline $\begin{array}{l}\text { PP/PA6 3- } \\
\text { plied filter }\end{array}$ & 1.08 & $5.9-25$ & 7.2 & 88 & 2.5 & $2.9 \pm 0.2$ \\
\hline $\begin{array}{l}\text { PP/PA6 4- } \\
\text { plied filter }\end{array}$ & 1.38 & $4.0-25$ & 5.4 & 87 & 3.3 & $2.0 \pm 0.4$ \\
\hline
\end{tabular}


Table 5. Water contact angles and filtration properties of the un-treated and corona-treated PP/PA6 fibrous filters for different durations.

\begin{tabular}{|c|c|c|c|c|c|}
\hline \multirow{6}{*}{ Structure } & \multicolumn{5}{|c|}{ Filter thickness $=0.74 \mathrm{~mm}$} \\
\hline & \multicolumn{5}{|c|}{ Fiber Size $=3.7 \pm 3.3 \mu \mathrm{m} \times 0.85 \pm 0.51 \mu \mathrm{m}$} \\
\hline & \multicolumn{5}{|c|}{ Surface Area $=2.83 \pm 0.04 \mathrm{~m}^{2} / \mathrm{g}$} \\
\hline & \multicolumn{5}{|c|}{ Pore Size Range = $8.1-49 \mu \mathrm{m}$} \\
\hline & \multicolumn{5}{|c|}{ Mean Pore Size $11 \mu \mathrm{m}$; Porosity $=86.6 \%$} \\
\hline & \multicolumn{5}{|c|}{ Influent $\mathrm{C}_{\text {water }}=2.5 \times 10^{3} \mathrm{ppm}$} \\
\hline Corona-treatment time (s) & 0 & 10 & 30 & 60 & 120 \\
\hline Starting water contact angle $\left({ }^{\circ}\right)$ & 124 & 125 & 128 & 60 & 0 \\
\hline Ending water Contact Angle $\left(^{\circ}\right)$ & 124 & 78 & 51 & 0 & 0 \\
\hline Filtration $\Delta \mathrm{P}(\mathrm{psi})$ & 0.7 & 0.6 & 0.5 & 0.2 & N/A \\
\hline Effluent $\mathrm{C}_{\text {water }}\left(\mathrm{x} 10^{2} \mathrm{ppm}\right)$ & $3.7 \pm 0.3$ & $6.7 \pm 0.8$ & $9.5 \pm 0.4$ & $11.4 \pm 1.2$ & N/A \\
\hline
\end{tabular}


Table 6. The water droplet volumes and the corresponding filter tilting angles at instability for an untreated and a 60s-treated PP/PA6 fibrous filter

\begin{tabular}{ccc}
\hline & Untreated PP/PA6 filter & $\begin{array}{c}\text { Treated PP/PA6 filter } \\
\text { (Treatment time }=60 \mathrm{~s})\end{array}$ \\
\hline Droplet volume, V $(\mu \mathrm{L})$ & $\begin{array}{c}\text { Filter tilting angle at droplet } \\
\text { instability, } \alpha\left(^{\circ}\right)\end{array}$ & $\begin{array}{c}\text { Filter tilting angle at droplet } \\
\text { instability, } \alpha\left(^{\circ}\right)\end{array}$ \\
\hline 40 & 63 & Out of limit \\
\hline 55 & 47 & Out of limit \\
\hline 60 & 45 & Out of limit \\
\hline 65 & 38 & 72 \\
\hline
\end{tabular}

